\title{
Gene expression identifies metabolic and functional differences between intramuscular and subcutaneous adipocytes in cattle
}

Nicholas J. Hudson ${ }^{1 *}$ (D) Antonio Reverter ${ }^{2}$, William J. Griffiths ${ }^{3}$, Eylan Yutuc ${ }^{3}$, Yuqin Wang ${ }^{3}$, Angela Jeanes ${ }^{4}$, Sean McWilliam², David W. Pethick ${ }^{5+}$ and Paul L. Greenwood ${ }^{6+}$

\begin{abstract}
Background: This study used a genome-wide screen of gene expression to better understand the metabolic and functional differences between commercially valuable intramuscular fat (IMF) and commercially wasteful subcutaneous (SC) fat depots in Bos taurus beef cattle.

Results: We confirmed many findings previously made at the biochemical level and made new discoveries. The fundamental lipogenic machinery, such as ACACA and FASN encoding the rate limiting Acetyl CoA carboxylase and Fatty Acid synthase were expressed at 1.6-1.8 fold lower levels in IMF, consistent with previous findings. The FA elongation pathway including the rate limiting ELOVL6 was also coordinately downregulated in IMF compared to SC as expected. A 2-fold lower expression in IMF of ACSS2 encoding Acetyl Coenzyme A synthetase is consistent with utilisation of less acetate for lipogenesis in IMF compared to SC as previously determined using radioisotope incorporation. Reduced saturation of fat in the SC depot is reflected by 2.4 fold higher expression of the SCD gene encoding the $\Delta 9$ desaturase enzyme. Surprisingly, $\mathrm{CH} 25 \mathrm{H}$ encoding the cholesterol 25 hydroxylase enzyme was 36 fold upregulated in IMF compared to SC. Moreover, its expression in whole muscle tissue appears representative of the proportional representation of bovine marbling adipocytes. This suite of observations prompted quantification of a set of oxysterols (oxidised forms of cholesterol) in the plasma of 8 cattle exhibiting varying IMF. Using Liquid Chromatography-Mass Spectrometry (LC-MS) we found the levels of several oxysterols were significantly associated with multiple marbling measurements across the musculature, but (with just one exception) no other carcass phenotypes.
\end{abstract}

Conclusions: These data build on our molecular understanding of ruminant fat depot biology and suggest oxysterols represent a promising circulating biomarker for cattle marbling.

Keywords: Bovine fat depots, Kidney, Omental, Intermuscular

\footnotetext{
* Correspondence: n.hudson@uq.edu.au

†David W. Pethick and Paul L. Greenwood joint senior authors.

${ }^{1}$ School of Agriculture and Food Sciences, University of Queensland, Gatton,

QLD, Australia

Full list of author information is available at the end of the article
}

(c) The Author(s). 2020 Open Access This article is distributed under the terms of the Creative Commons Attribution 4.0 International License (http://creativecommons.org/licenses/by/4.0/), which permits unrestricted use, distribution, and reproduction in any medium, provided you give appropriate credit to the original author(s) and the source, provide a link to the Creative Commons license, and indicate if changes were made. The Creative Commons Public Domain Dedication waiver (http://creativecommons.org/publicdomain/zero/1.0/) applies to the data made available in this article, unless otherwise stated. 


\section{Background}

Deposition of marbling (IMF) fat in cattle is commercially valuable. It has a positive impact on organoleptic properties of meat such as flavour, juiciness and tenderness [1]. On the other hand, the other fat depots including subcutaneous and organ fats do not add value to meat cuts. Excessive amounts of these undesirable depots are often associated with carcasses expressing high levels of IMF. Therefore, there is a continued interest in developing our understanding of the metabolic and functional differences between the various fat depots with a view to better uncouple IMF and SC deposition.

Marbling has been considered a late maturing trait only becoming visible after the other depots, this despite relative rates of increase in IMF being similar to other fat depots [2-4]. Furthermore, while breeds of cattle like Wagyu and Hanwoo are pre-disposed to precociously and selectively develop IMF, the underlying genetic, cellular, biochemical and physiological mechanisms have not been well established [5]. We know from previous work that marbling adipocytes tend to be relatively small [6] and comprising more saturated fatty acids [7] compared to those in the SC depot. Developmentally, marbling adipocytes are thought to arise from differentiation and lipid filling of fibroblasts within perimysial connective tissue [8].

In terms of differential metabolism between depots, previous biochemical evidence points to IMF having relatively slow rates of lipogenesis in both cattle [9] and pigs [10] and under certain nutritional circumstances a substrate preference for glucose carbon over acetate when compared to SC $[6,11]$. Post-weaning diets tailored to these specific metabolic properties of IMF, such as strategic feeding with high energy concentrate, have had mixed success [12] for reasons not certain but which probably include net energy available for tissue deposition. A recent review emphasises castration, digestion and absorption of feed, glucose availability and vitamin $\mathrm{A}, \mathrm{D}$ and $\mathrm{C}$ levels as important factors in marbling development [13]. However, overall it is clear that there is scope for a deeper understanding of ruminant fat depot metabolism and biology that may inform new animal management strategies.

The emergence of genome-wide transcriptome screening technologies provides an opportunity to assess entire biochemical pathways in quantitative detail not yet possible at other levels of biological organisation. Here, we analyse data from 5 bovine fat depots (IMF, SC, intermuscular, kidney and omental), with a particular focus on the IMF versus SC depot comparison. These functional genomic data are one component of a much larger animal experiment exploring cattle genotype by nutritional effects on fat depot biology [12]. Tissue samples for the present study were taken from 26 month-old steers of 3 genotypes, Angus, Hereford and Wagyu $x$ Angus following high energy nutrition in a feedlot for 259 days. The Herefords had relatively low IMF and high $\mathrm{SC}$ whereas the Angus and Wagyu $\mathrm{x}$ Angus were higher IMF and lower SC.

We explored two analytical approaches both focussing on differential fat depot biology, but with one hypothesis-driven and one hypothesis-free. The former tested the mRNA expression of canonical ruminant fatty acid synthesis and degradation pathways and compared the output against prior biochemical expectation. The latter explored genome-wide patterns of gene expression with an aim of making new metabolic and functional discoveries in an unbiased manner. The across depot genome-wide transcriptome data submitted with this research article represents a uniquely powerful data resource within the field of ruminant fat biology.

\section{Results \\ Hypothesis-free screen \\ Data driven hierarchical clustering}

Each fat depot could be clearly discriminated by gene expression as the data from each breed clustered at the depot level (Fig. 1). Put another way, the gene expression differences between fat depots clearly overwhelm any breed differences within a depot. Moreover, IMF was separated from the other 4 fat depots. Of the remaining 4 depots, Inter and Omen were most closely related, followed by Kid then SC. Given SC appears the most functionally divergent of the 'pure' (i.e. we can make a confident assertion of no muscle contamination) fat depot samples, we elected to compare all depots to SC in turn.

\section{Differential expression (DE) analysis}

SC versus all other fat depots We plotted all fat depots minus SC and annotated the extreme differentially expressed (DE) genes (Fig. 2). Two consistent outlier genes by expression profile in SC are HOXA10 and DLK1 $(P<0.01)$. The log2 normalised mean expression of these two genes in each fat depot is compared in Table 1. Other genes of interest for their extreme expression in at least one depot are TDH, TMEFF2 and CLDN10, also tabulated in Table 1.

We next focussed on the particular IMF versus SC comparison in more detail.

IMF versus $\mathrm{SC}$ In the IMF versus $\mathrm{SC}$ comparison the most extreme 1\% (145 out of 14, 476) downregulated genes in IMF enriched for 'humoral immune response' (Hypergeometric statistic, FDR q-value $=0.00017$ ) based on the presence of genes including $C F B, C X C L 3, C D 163$, 


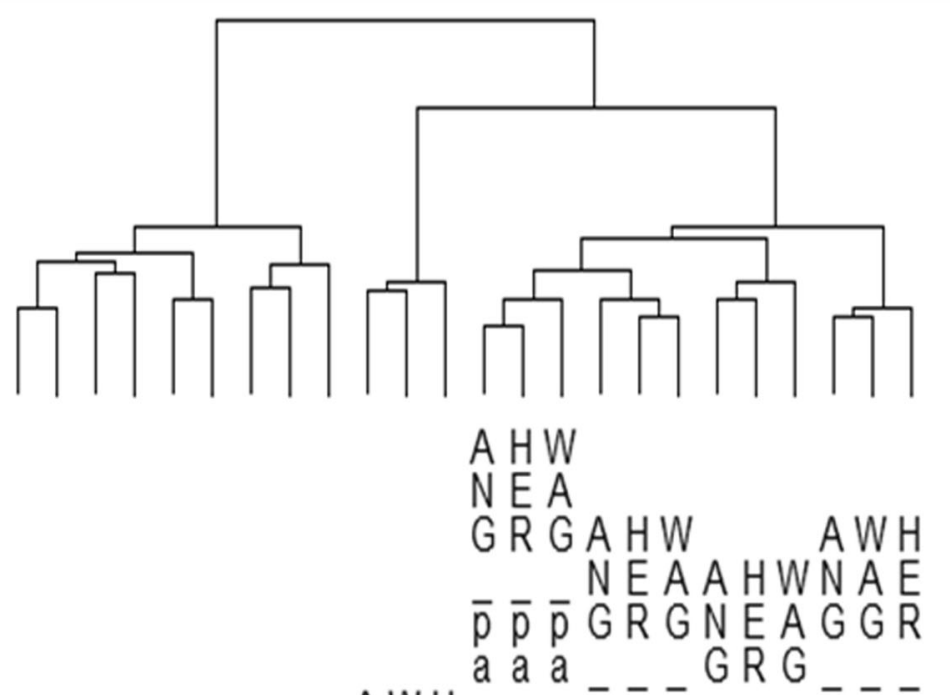

Fig. 1 A dendrogram of relationships between the various fat depots based on the expression profiles of 10,000 genes selected at random. The treatment labels are breed (Ang = Angus, Her = Hereford, Wag = Wagyu $\times$ Angus), diet (past = pasture, supp = supplement), Kill number (2 or 5) and finally tissue ( $L D=$ longissimus dorsi muscle, IMF = intramuscular fat, Inter Mus - intermuscular fat, Omental = omental fat, Kidney = kidney fat, SC rump = subcutaneous rump fat). The first major split shows that the LD muscle is discriminated from all fat depots, reflecting muscle-specific patterns of gene expression. All fat depots are clearly resolved i.e. the three breeds form fat depot specific clusters in all cases which shows the various depots all possess diagnostic genome-wide expression signatures. IMF was awarded a unique branch within the fat tree, but this is presumably influenced by muscle derived gene expression arising from small amounts of LD muscle contamination

CD36 and CD163L1). To generate this ranked list we used a modified DE metric called Phenotypic Impact Factor (PIF), which is a product of $\mathrm{DE}$ and average abundance across the treatments of interest. The extreme 20 most downregulated genes are shown in Table 2.

From Table 2 it can be seen that various aspects of fat metabolism (SCD, DGAT2, FASN, ACSS2, AGPAT2, CIDEA, GOS2), extracellular matrix biology (TIMP4, $S P A R C, C C D C 80)$ and some inflammation related genes (CXCL3, CD163) are prominently featured in those transcripts whose expression is lower in IMF than SC. The extreme 5\% downregulated genes (PIF) in IMF enriched for 'lipid metabolic process' $($ FDR q-value $=1.04 \mathrm{e}-16$ ) and 'defense response' (FDR q-value 1.88 e-15) in line with those observations, but these functional enrichments were not as extreme as the top hit 'regulated exocytosis' (FDR q-value $=5.11 \mathrm{e}-27$ ).

On the other hand, the upregulated $1 \%$ in IMF enriched very significantly for 'muscle system process' $($ FDR q-value $=3.54 \mathrm{e}-46)$ based on 44 genes generally regarded as either muscle-specific (e.g. myoglobin) or very highly expressed in muscle cells (such as numerous specialised myosin light and heavy chain isoforms as illustrated by MYL2 and MYH2). A more lenient $5 \%$ extreme upregulated PIF (or 724 genes) marginally lessens the impact of the muscle specific detection (FDR $\mathrm{q}$-value $=3.44 \mathrm{e}-44)$. 

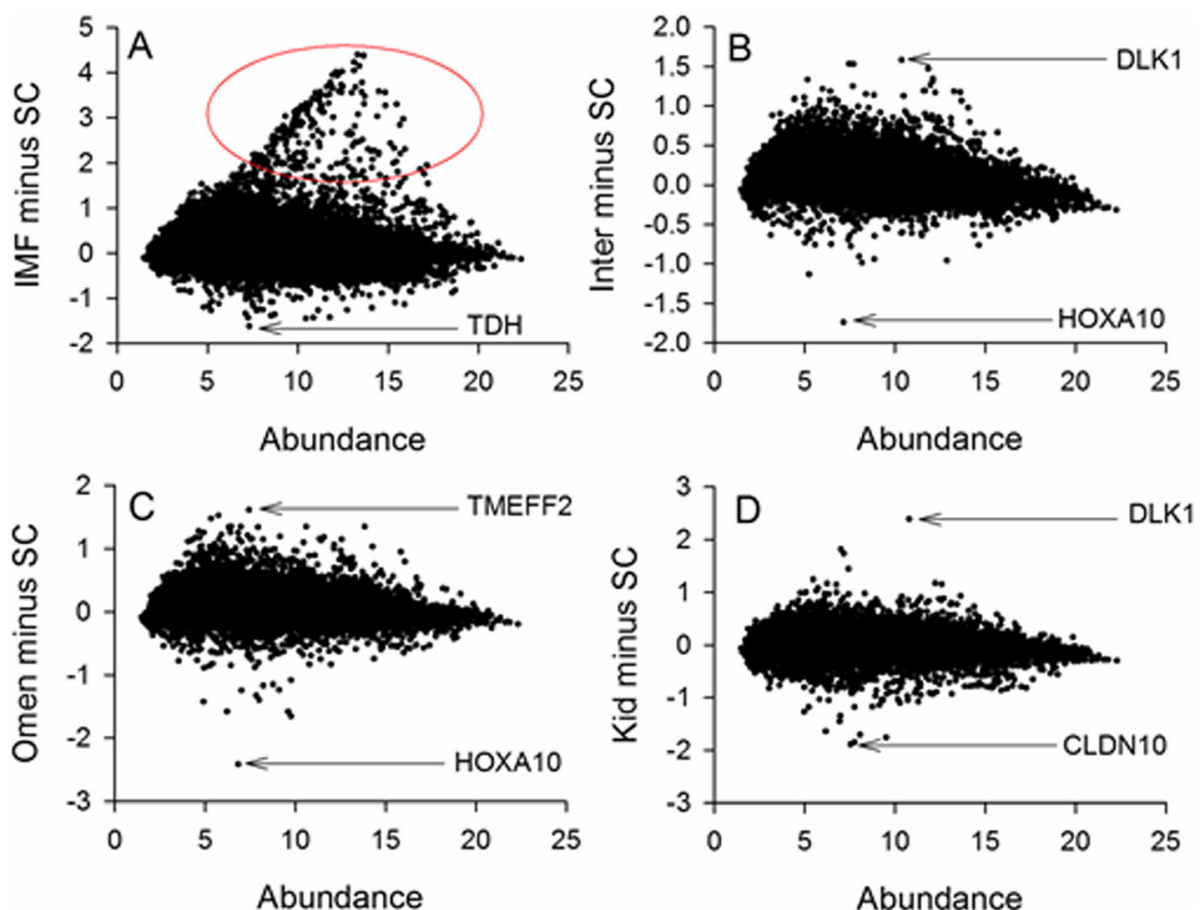

Fig. 2 The Minus Average (MA) plots of SC versus all other depots (a) IMF (b) Inter (c) Omen and (d) Kid. It is clear that SC tends to have relatively high expression of HOXA10 and relatively low expression of DLK1. The red circle in (a) denotes an unusual triangular shaped protuberance atypical of MA plots and whose functional characteristics were subsequently explored

It is clear from these functional enrichments that the dissected IMF must have contained a very small amount of longissimus dorsi (LD) muscle contamination not present in the other fat depots. Genes strongly expressed by the muscle cells in the IMF sample therefore appear to make up the majority of the atypical triangle shaped protuberance in the IMF versus SC MA plot (as highlighted by the red circle on Fig. 2a). We have elected not to tabulate the extreme upregulated genes in IMF versus $\mathrm{SC}$, as this would simply return a list of genes dominated by mRNA encoding muscle structural and muscle metabolic proteins.
To better determine the cellular origin (marbling adipocyte versus myocyte) of many of the upregulated genes in the dissected IMF we first computed Differential Expression (DE) between pure LD (nearly all muscle, small amount of IMF) and SC (all fat, no muscle contamination). We then identified genes which had nominally $>4$ fold higher expression in LD than SC as likely being transcribed predominantly from muscle cells, not fat cells. This yielded a list of 171 genes (hypergeometric FDR q value of 2.04e-39 for "muscle system process"), which we have then highlighted on the IMF versus SC plot (Fig. 3 panel a; Additional file 1). The highlighted

Table 1 Genes highly divergently expressed in SC versus all depots (log2 normalised mean expression). P values are reported for both DE and PIF (based on the SC versus IMF comparison)

\begin{tabular}{llllllllll}
\hline Gene & Probe & LD & IMF & SC & Inter & Kid & Omen & Function & $P$ value (DE / PIF) \\
\hline HOXA10 & A_73_104882 & 6.99 & 6.94 & 8.03 & 6.29 & 7.34 & 5.61 & $\begin{array}{l}\text { Differs among undifferentiated } \\
\text { pre-adipocytes between depots }\end{array}$ & $0.000265 / 0.013$ \\
DLK1 & A_73_P069591 & 11.84 & 11.27 & 9.58 & 11.16 & 11.97 & 10.54 & $\begin{array}{l}\text { Pre-adipocyte factor } \\
\text { Catalyses the conversion of }\end{array}$ & $0.00000185 / 0.0000225$ \\
TDH & A_73_P042901 & 5.99 & 6.49 & 8.11 & 7.61 & 7.29 & 7.53 & $\begin{array}{l}\text { C.000000276/0 } \\
\text { threonine to pyruvate }\end{array}$ & 0.000919 \\
TMEFF2 & A_73_109150 & 7.43 & 7.48 & 6.61 & 7.58 & 6.96 & 8.22 & $\begin{array}{l}\text { Membrane protein associated } \\
\text { with neurons }\end{array}$ & $0.0125 / 0.101$ \\
CLDN10 & A_73_106401 & 6.23 & 7.42 & 8.68 & 7.69 & 6.82 & 7.28 & $\begin{array}{l}\text { Claudin membrane protein } \\
\text { associated with adhesion and ion transport }\end{array}$ & $0.0000376 / 0.00343$ \\
\hline
\end{tabular}


Table 2 The 20 most downregulated genes in IMF versus SC (log2 normalised mean expression). P values are reported for both DE and PIF (based on the SC versus IMF comparison)

\begin{tabular}{lllllll}
\hline Gene & Probe & LD & IMF & SC & Function & $P$ value (DE / PIF) \\
\hline SCD & A_73_P252739 & 14.46 & 15.33 & 16.47 & Desaturation, fatty acid synthesis (oleic acid) & $0.000153 / 0.00000163$ \\
TF & A_73_109609 & 9.57 & 11.04 & 12.47 & Iron transport & $0.00000421 / 0.00000731$ \\
CXCL3 & A_73_108688 & 11.34 & 12.09 & 13.36 & Secreted growth factor, inflammation & $0.0000332 / 0.0000151$ \\
DGAT2 & A_73_118582 & 14.51 & 15.86 & 16.72 & Final reaction in TAG synthesis & $0.00259 / 0.000132$ \\
PCK2 & A_73_P102501 & 12.44 & 13.49 & 14.44 & Adipogenesis, mitochondrial & $0.00112 / 0.0003$ \\
RAB9B & A_73_104413 & 12.83 & 14.19 & 15.09 & Endosome to golgi transport, membrane trafficking & $0.00180 / 0.000326$ \\
CFB & A_73_118840 & 10.91 & 11.98 & 12.98 & Complement factor B & $0.000681 / 0.000528$ \\
FASN & A_73_P174332 & 16.08 & 17.23 & 17.94 & Synthesis of long chain saturated fatty acids & $0.00918 / 0.000528$ \\
ACSS2 & A_73_P037091 & 12.58 & 13.11 & 14.01 & Activation of acetate for lipid synthesis & $0.00180 / 0.000670$ \\
TDH & A_73_P042901 & 5.99 & 6.49 & 8.11 & Catalyses I-threonine degradation & $0.00117 / 0.000919$ \\
CD163 & A_73_P091466 & 7.18 & 7.81 & 9.20 & Inflammation, strongly expressed by macrophages & $0.00000719 / 0.000928$ \\
GOS2 & A_73_100624 & 13.72 & 15.16 & 15.91 & FA, TAG and ketone metabolism & $0.00666 / 0.00106$ \\
TIMP4 & A_73_112376 & 14.43 & 14.97 & 15.73 & Inhibitor of matrix metalloproteinases & $0.00614 / 0.00105$ \\
AGPAT2 & A_73_118412 & 17.80 & 18.26 & 18.89 & De novo phospholipid synthesis, endoplasmic reticulum & $0.0168 / 0.00102$ \\
CCDC80 & A_73_P035251 & 15.24 & 16.08 & 16.79 & Extracellular matrix & $0.00918 / 0.00119$ \\
QPRT & A_73_P039661 & 11.69 & 12.80 & 13.62 & NAD de novo biosynthesis \\
SPARC & A_73_P300606 & 17.10 & 17.85 & 18.43 & Extracellular matrix organisation & $0.00370 / 0.00204$ \\
CIDEA & A_73_100290 & 12.16 & 12.84 & 13.64 & Regulation of lipolysis & $0.0239 / 0.00258$ \\
\hline
\end{tabular}

genes, which have been identified using a numerical strategy, all clearly fall in the triangular shaped protuberance distorting the overall IMF versus SC MA distribution, indicating that this atypical data distribution is indeed a consequence of muscle contamination.

This set of analyses reinforces the conclusion that prima facie those outlier genes in the IMF versus SC are almost certainly driven by the presence of some LD muscle in the 'pure' IMF sample and therefore need to be interpreted cautiously. The impact of the 'contaminating' muscle derived RNA on the expression of most of the remaining genes is harder to foresee, as there will be a continuum of shared expression between the myocytes and adipocytes, depending on the particular gene being investigated. In this submission, we have provided the normalised mean expression for LD in addition to all the fat depots for the 34,227 probes (Additional file 2) so the interested reader can assess the possible impact of contaminating LD on a case by case basis. This is also the reason why we have included the LD normalised mean expressions in each table for comparison. The outcome of a multiple criteria thresholding process is described below ("Structural differences between marbling adipocytes and the other fat depot adipocytes"). This multiple thresholding does allow us to define lists of genes whose expression likely arises from the IMF adipocytes themselves and therefore can be considered biologically informative of the IMF depot.
Mitoproteome In an effort to explore the behaviour of the mitochondria in our understanding of the metabolism of IMF versus SC metabolism we quantitated the collective expression of those mRNA known to encode mitochondrial proteins. Using the downloaded mitochondrial protein database we matched 886 of these in our data, 595 of which were higher in IMF than SC, but only 287 of which were lower (Fig. 3 panel b). This is a significant deviation $(P=2.29 \mathrm{e}-26)$ from the null expectation of equilibrium (i.e. symmetrically distributed around 0 , with 443 above and 443 below) assessed by binomial distance. This upward skew is consistent with IMF having a higher mitochondrial content and / or mitochondrial activity than SC, but the presence of some high mitochondrial content LD muscle in the IMF depot is presumably influencing the result. Notable among the mitochondrial genes strongly downregulated in IMF compared to SC (despite the probable impact of the contaminating muscle) is $P C K 2$.

Structural differences between marbling adipocytes and the other fat depot adipocytes To better account for and visualise the effect of the contaminating LD on the IMF gene expression we colour coded the Minus Average (MA) plot comparing IMF to SC based on a formal numerical analysis that accounts for the presence of contaminating LD in the IMF sample (Fig. 4). Colour coding each gene individually in this manner visually 

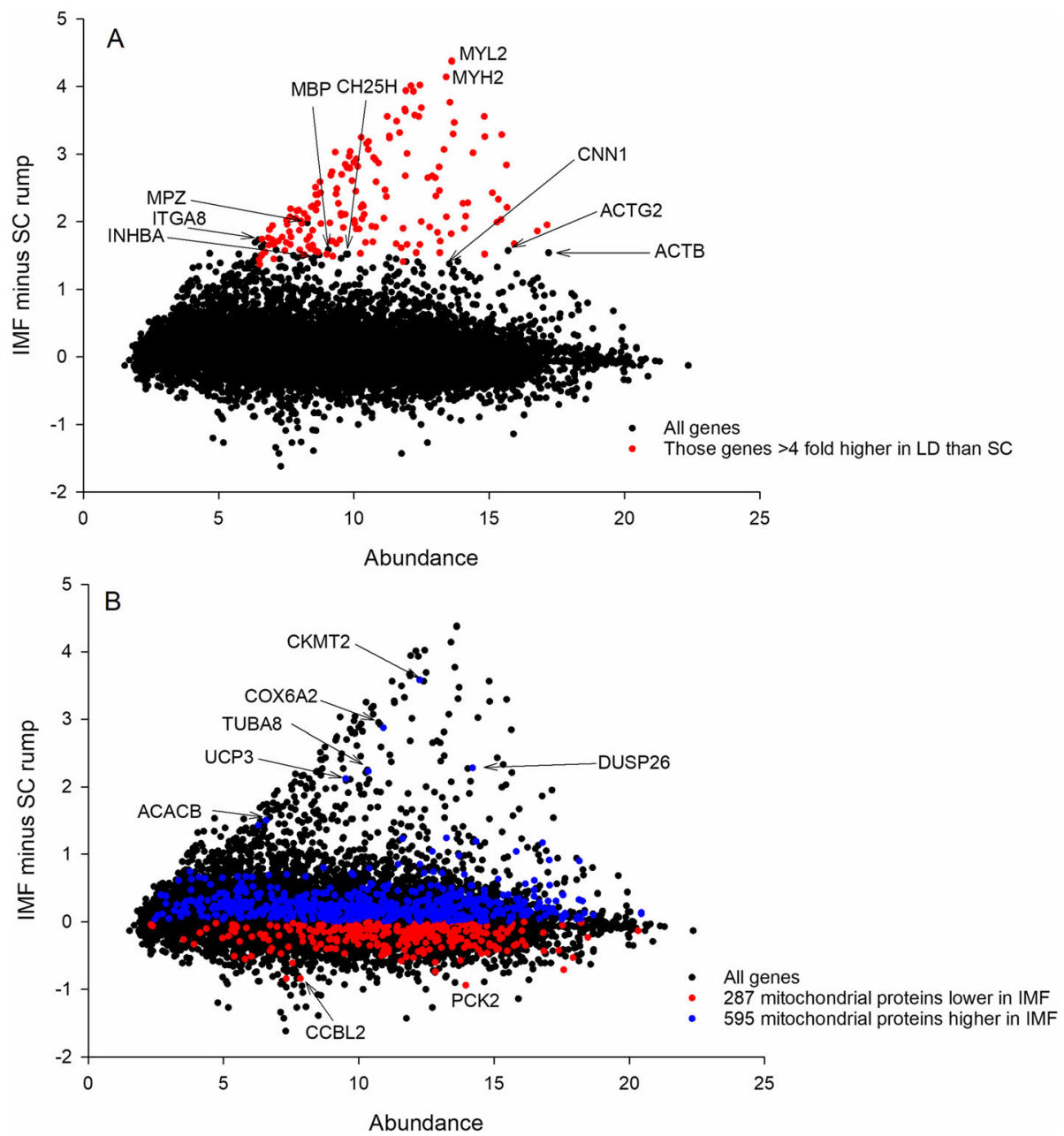

Fig. 3 Minus Average (MA) plots of IMF minus SC. a Red dots are those 168 mRNA 4 fold higher in LD than SC indicating the atypical triangular protuberance comes from contaminating LD (b) the 886 mRNA encoding mitochondrial proteins for which we detected matches in our data, blue above 0 , red below 0 . There is a significant skew upwards (595 above the 0 line) from the null expectation of equilibrium (data centred on 0 , with 443 falling on either side of the line)

highlights those genes (such as $\mathrm{CH} 25 \mathrm{H}$ ) that are most likely higher in IMF than SC because of particularly high expression from the IMF adipocytes per se and not because of the contaminating LD muscle. Yellow / orange dots above 0 on the y axis are colour coded in this manner because they have a higher expression in IMF than LD which implies their observed higher expression in IMF than SC is a true feature of the marbling adipocytes. This logic also applies to the purple dots below 0 on the $\mathrm{y}$ axis.

To identify a short list of these genes whose high expression is confidently ascribed to the marbling adipocytes and not contaminating skeletal muscle we used a multiple criteria thresholding approach. To begin with, we asked the question, "which mRNA are more highly expressed in IMF than the average of all other fat depots by $<1.32$ fold (a difference of 0.4 on the $\log 2$ scale) and also much more highly expressed in IMF than LD $(>2$ fold)." This analysis returns a list of 49 genes whose expression is more confidently derived from marbling adipocytes (Additional file 1). There is no functional enrichment for 'muscle systems process.' Tabulating the top 20 of these ranked on IMF SC Phenotypic Impact Factor (PIF) yields the gene list in Table 3.

In this adapted list whose expression signals are derived from marbling adipocytes there is functional enrichment for components of the cytoskeletal architecture (CNN1, ACTA2, MYH11, ACTB, ACTRT2, SORBS2, KRT18). Other genes of interest include a) $\mathrm{CH} 25 \mathrm{H}$ which encodes an enzyme that catalyses the production of a particular oxysterol metabolite b) the microRNA MIR145 and c) CTPS2 which catalyses the production of CTP, a high energy analog to ATP but whose hydrolysis is coupled to a restricted subset of metabolic reactions including glycerophospholipid synthesis. Similarly, querying the full list for those genes 


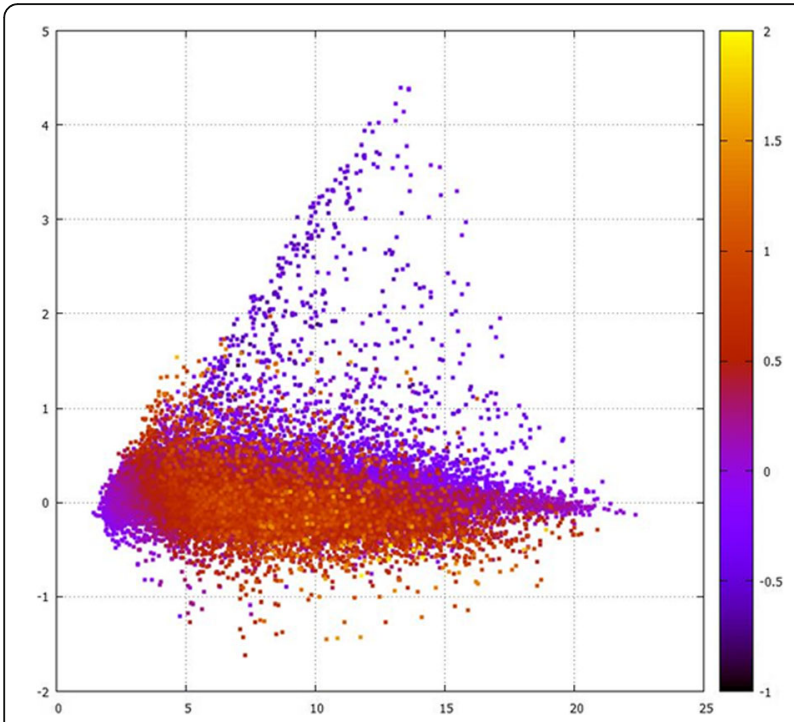

Fig. 4 Modified Minus Average (MA) plot of IMF versus SC to allow the visualisation of the real IMF signal, independent of the LD contamination. Here, we have colour coded each mRNA using a formal numerical approach such that the expression of those highlighted in red and yellow tones (above 0) and purple (below 0) are most likely derived from the IMF adipocytes themselves and not from contaminating LD muscle. To achieve the colour coding we exploited the difference in expression detected between the 'pure' IMF and 'pure' LD muscle samples. For example, if an mRNA has higher expression in IMF than in LD then we conclude it likely derives from the marbling adipocytes. The mRNA encoding $\mathrm{CH} 25 \mathrm{H}$ exemplifies this logic. In addition to being higher in IMF than SC, it is also higher in IMF than LD. In terms of exact position on the plot, the mRNA encoding $\mathrm{CH} 25 \mathrm{H}$ has an A value of 9.77 and an $\mathrm{M}$ value of 1.52

whose expression $>1.68$ fold high in IMF than the other fat depots combined and also higher in IMF than LD by any value yields a list of 76 genes (Additional file 1 ). There is no functional enrichment for 'muscle systems process.'

Moreover, in another analysis directed at the specific IMF versus SC comparison, we reported those genes > 2 fold higher expression in IMF than SC (without considering expression in the other fat depots), and higher expression in IMF than LD (by any amount). This produced a list of 73 genes (Additional file 1) including those encoding proteins in extracellular matrix organisation (GFAP, COL28A1, COL2A1, ITGA8, TNC, SNCA, MYH11, MKX, COL4A6 and TNFRSF11B). Manual curation of the gene list highlighted 3 additional functional groups of interest that are relatively upregulated in IMF versus SC: cholesterol metabolism (PMP2, CH25H, CYP4B1), retinoic acid metabolism (STRA6, MEST) and insulin and carbohydrate metabolism (GRB14, NR4A3 and MOXD1). The expression profiles for the genes within these three functional groupings are shown in Table 4.
Cluster analysis of the normalised mean expression of the 73 genes across the 5 fat depots and LD muscle indicates the expression of this panel of genes is diagnostic of the IMF depot (Fig. 5). This can be contrasted with the original clustering performed on a randomly selected 10,000 genes whose first branch separates the LD muscle, and not IMF, from all the fat depots. The clustering on rows clusters genes who are co-expressed across tissues. Some of the clusters reflect known functional relatedness, with $K R T 8$ with KRT18 reflecting keratin biology and ACTA2 and MYH11 reflecting cytoskeletal biology.

Of those 41 genes we identified as more lowly expressed in IMF than SC (by a minimum of 1.32 fold, but unlikely to be due to low expression in the contaminating LD because IMF expression is lower than LD) (Additional file 1) the most extreme 10 are shown in Table 5. There is no functional enrichment for 'muscle systems process.'

Importantly, none of these refined gene lists generated from our multiple criteria approach yield a significant hypergeometric enrichment for 'muscle system process.' This indicates that the multiple criteria thresholding method we have adopted here has successfully eliminated those genes representative of muscle contamination in the IMF sample. The summaries of the number of genes identified by the various single and multiple criteria approaches, and their respective hypergeometric functional enrichments, are found in Tables 6 and 7, respectively.

\section{Hypothesis-driven analysis Lipogenesis in adipocytes}

To formally connect these mRNA data to traditional biochemical knowledge, we identified and tabulated the expression profiles of those genes encoding ratelimiting enzymes and other proteins considered influential in the various lipogenic processes (Table 8). This includes the following biochemical processes: precursor transport into the adipocyte cells (glucose and free FA), aspects of intermediate energy metabolism (glycolysis and pyruvate metabolism), de novo FA synthesis, FA elongation, FA desaturation, FA esterification with glycerol and finally the supply of reducing power equivalents.

We can see that some of these canonical lipogenic pathways show clear, consistent patterns of gene expression based on the key enzymes. For example, de novo FA synthesis (FASN and ACACA 1.63-1.79 fold), FA elongation (ELOVL6 1.61 fold), desaturation (SCD 2.2 fold), supply of reducing power equivalents (G6PD, ME1 and $P G D 1.33,1.43$ and 1.51 fold), esterification (GPAM and DGAT2 1.3 to 1.82 fold) and lipolysis (PNPLA2, LIPE, MGLL and PLIN2 1.31, 1.33, 1.39 to 1.61 fold) are 
Table 3 Genes more highly expressed in IMF than all other fat depots by at least 1.32 fold whose expression appears driven by marbling adipocytes (IMF expression greater than 2 fold higher than LD). Normalised expression data expressed as log2 values. $P$ values are reported for both DE and PIF (based on the SC versus IMF comparison)

\begin{tabular}{|c|c|c|c|c|c|c|c|c|c|}
\hline Gene & Probe & LD & IMF & SC & Inter & Kid & Omen & Function & $P$ value (DE / PIF) \\
\hline CNN1 & A_73_116127 & 12.93 & 14.22 & 12.84 & 13.20 & 12.98 & 12.88 & Calponin 1, cytoskeleton & $0.0000974 / 0.00000727$ \\
\hline ACTA2 & A_73_102355 & 15.75 & 16.79 & 15.69 & 15.96 & 15.88 & 15.78 & Actin alpha 2, cytoskeleton & $0.00180 / 0.0000175$ \\
\hline MYH11 & A_73_103577 & 13.12 & 14.33 & 13.03 & 13.31 & 13.16 & 13.06 & $\begin{array}{l}\text { Myosin heavy chain } 11, \\
\text { cytoskeleton }\end{array}$ & $0.000239 / 0.0000191$ \\
\hline$A C T B$ & A_73_P082186 & 10.63 & 12.12 & 10.64 & 11.09 & 10.85 & 10.68 & Actin beta, cytoskeleton & $0.0000295 / 0.000000000212$ \\
\hline $\mathrm{CH} 25 \mathrm{H}$ & A_73_113925 & 9.18 & 10.53 & 9.01 & 9.83 & 9.69 & 9.82 & $\begin{array}{l}\text { Cholesterol } 25 \text { hydroxylase, } \\
\text { inflammation, lipid metabolism }\end{array}$ & $0.0000179 / 0.000334$ \\
\hline ACTRT2 & A_73_107737 & 7.99 & 9.25 & 7.78 & 8.26 & 8.04 & 8.40 & Actin related protein $\mathrm{T} 2$ & 0.0000334 / 0.00230 \\
\hline INHBA & A_73_108840 & 8.04 & 9.18 & 7.72 & 8.27 & 7.94 & 8.32 & $\begin{array}{l}\text { Inhibin A, Growth and Differentiation } \\
\text { Factor, Hormone, binds ACVR2A }\end{array}$ & 0.0000377 / 0.00283 \\
\hline SORBS2 & A_73_P046131 & 10.85 & 12.12 & 11.06 & 11.27 & 11.15 & 11.27 & $\begin{array}{l}\text { Sorbin and SH3 domain containing. } \\
\text { Cytoskeleton, lipid raft interaction }\end{array}$ & $0.0026 / 0.00301$ \\
\hline NDRG4 & A_73_109411 & 9.76 & 10.80 & 9.63 & 9.92 & 9.91 & 9.82 & $\begin{array}{l}\text { Many developmental processes, ERK } \\
\text { signalling, plasma membrane }\end{array}$ & $0.000922 / 0.00352$ \\
\hline TNC & A_73_108252 & 8.03 & 9.22 & 7.83 & 8.67 & 8.09 & 7.87 & Tenascin, extracellular matrix & $0.0000867 / 0.00379$ \\
\hline RAMP3 & A_73_P043356 & 6.56 & 7.92 & 6.34 & 7.03 & 6.69 & 6.81 & $\begin{array}{l}\text { Trans-membrane, transports } \\
\text { calcitonin receptor-like protein }\end{array}$ & $0.00000824 / 0.00577$ \\
\hline TNMD & A_73_110381 & 6.16 & 7.19 & 5.51 & 6.45 & 5.34 & 5.33 & $\begin{array}{l}\text { Tenomodulin, genetic variants } \\
\text { associated with type II diabetes }\end{array}$ & $0.00000212 / 0.00829$ \\
\hline KRT18 & A_73_118812 & 5.99 & 7.39 & 5.77 & 6.04 & 5.83 & 6.68 & Keratin 18 , cytoskeleton & 0.00000484 / 0.0087 \\
\hline CTPS2 & A_73_113928 & 13.04 & 14.25 & 13.55 & 13.63 & 13.46 & 13.50 & $\begin{array}{l}\text { CTP synthase 2, rate limiting } \\
\text { enzyme for CTP production from UTP. }\end{array}$ & $0.0404 / 0.0157$ \\
\hline TAGLN & A_73_P291026 & 9.36 & 10.43 & 9.51 & 9.90 & 9.67 & 9.72 & Transgelin, actin cross-linking & $0.0085 / 0.0186$ \\
\hline GJA5 & A_73_P048871 & 9.66 & 10.69 & 9.80 & 10.20 & 10.23 & 10.23 & $\begin{array}{l}\text { Connexin gene family, plasma } \\
\text { membrane }\end{array}$ & $0.0107 / 0.0147$ \\
\hline DKK3 & A_73_116904 & 10.33 & 11.58 & 10.77 & 11.13 & 11.12 & 10.96 & $\begin{array}{l}\text { Wnt signalling, many } \\
\text { developmental processes }\end{array}$ & $0.0194 / 0.0236$ \\
\hline MKX & A_73_105199 & 5.25 & 6.34 & 4.97 & 5.75 & 4.96 & 5.11 & Collagen biosynthesis & $0.000109 / 0.0490$ \\
\hline MIR145 & A_73_105615 & 12.31 & 13.61 & 13.04 & 13.07 & 12.96 & 13.01 & microRNA, little known & $0.0857 / 0.0515$ \\
\hline COL28A1 & A_73_107519 & 4.90 & 6.28 & 4.93 & 5.42 & 5.49 & 5.05 & Extracellular matrix & $0.0137 / 0.0540$ \\
\hline
\end{tabular}

rather consistently downregulated in IMF versus SC. On the other hand, there are patterns of both up and downregulation within other pathways. Glycolytic flux and pyruvate metabolism are two such pathways, comprising key genes exhibiting both higher and lower expressed in IMF than SC. The $\sim 4$ fold upregulation of PFKM and $P K M$ (i.e. muscle specific isoforms of the enzymes) in IMF versus SC glycolytic flux can most likely be attributed to LD contamination.

We examined a subset of core lipogenic processes in more detail at the whole pathway level. The normalised mean expression data for the FA biosynthesis and FA elongation pathways are shown in Additional file 3. We next manually explored the gene lists, detecting a number of particular isoforms as being upregulated in IMF for esterification and glycerolipid synthesis. These have been tabulated (Table 9) and are contrary to the pathway output (based on GPAM, DGAT) outlined in Table 8. The expression of AGPAT9 (esterification) and MBOAT2 (glycerolipid synthesis) are potentially noteworthy, with a DE in excess of 1.4 fold higher in IMF compared to SC that is not attributable to LD contamination.

\section{qRT-PCR}

$\mathrm{CH} 25 \mathrm{H}$ was found to be significantly $(P<0.0001 ; 2$ Tailed Mann Whitney U Test) more highly expressed in dissected IMF than SC by $\sim 34$-fold using the first primer pair (Fig. 6) and 38-fold using the second primer pair, yielding a 36 fold average. The direction of change is the same as for the microarray probe but the absolute difference is $\sim 10$ fold higher. 
Table 4 Gene expression patterns of those genes identified by multiple criteria ( $>2$ fold higher expression in IMF than SC and also higher expression in IMF than LD) that encode proteins involved in cholesterol metabolism, retinoic acid metabolism and carbohydrate metabolism. $\mathrm{CH} 25 \mathrm{H}$ not shown here as its expression profile is documented in Table 3 (all values are log2 normalised mean expression). $P$ values are reported for both DE and PIF (based on the SC versus IMF comparison)

\begin{tabular}{|c|c|c|c|c|c|c|c|c|c|}
\hline Gene & Probe & LD & IMF & SC & Inter & Kid & Omen & Function & $\begin{array}{l}P \text { value (DE } \\
\text { PIF) }\end{array}$ \\
\hline PMP2 & A_73- 110378 & 3.74 & 5.44 & 3.90 & 3.78 & 3.74 & 3.72 & $\begin{array}{l}\text { Alias FABP8. Cholesterol binding. Found in cytoplasm, } \\
\text { extracellular exosomes and myelin sheath }\end{array}$ & $\begin{array}{l}0.0000138 / \\
0.0643\end{array}$ \\
\hline CYPAB1 & $\begin{array}{l}\text { A_73- } \\
\text { P033761 }\end{array}$ & 7.54 & 8.12 & 7.05 & 8.30 & 7.36 & 7.89 & $\begin{array}{l}\text { Member of the cytochrome p450 superfamily that } \\
\text { synthesises cholesterol, steroids and other lipids. Found } \\
\text { in the endoplasmic reticulum. }\end{array}$ & $\begin{array}{l}0.00238 / \\
0.0396\end{array}$ \\
\hline STRA6 & $\begin{array}{l}\text { A_73- } \\
106763\end{array}$ & 4.22 & 5.33 & 3.99 & 4.37 & 4.21 & 5.27 & $\begin{array}{l}\text { Membrane protein involved in the metabolism of retinol } \\
\text { involved in numerous developmental processes in many tissues. }\end{array}$ & $\begin{array}{l}0.000154 / \\
0.0969\end{array}$ \\
\hline MEST & $\begin{array}{l}\text { A_73- } \\
100042\end{array}$ & 7.27 & 7.79 & 6.62 & 7.25 & 6.87 & 7.06 & $\begin{array}{l}\text { Regulation of lipid storage and response to retinoic } \\
\text { acid. Found in the endoplasmic reticulum, extracellular } \\
\text { exosome and membrane. }\end{array}$ & $\begin{array}{l}0.00092 / \\
0.0335\end{array}$ \\
\hline GRB14 & $\begin{array}{l}\text { A_73- }_{-} \\
114416\end{array}$ & 5.13 & 5.73 & 4.61 & 5.04 & 5.33 & 5.46 & $\begin{array}{l}\text { Interacts with insulin receptors and insulin-like growth } \\
\text { factor receptors, having an inhibitory effect. }\end{array}$ & $\begin{array}{l}0.00149 / \\
0.1172\end{array}$ \\
\hline NR4A3 & $\begin{array}{l}\text { A_73- } \\
\text { P494813 }\end{array}$ & 5.57 & 6.19 & 5.11 & 6.04 & 5.85 & 6.08 & $\begin{array}{l}\text { Member of the steroid thyroid hormone retinoid } \\
\text { receptor superfamily. }\end{array}$ & $\begin{array}{l}0.00217 / \\
0.102\end{array}$ \\
\hline MOXD1 & $\begin{array}{l}\text { A_73- } \\
104693\end{array}$ & 4.16 & 5.09 & 4.06 & 4.44 & 4.47 & 4.87 & $\begin{array}{l}\text { Monoxygenase, localised to the endoplasmic reticulum and cell } \\
\text { membrane }\end{array}$ & $\begin{array}{l}0.0034 / \\
0.177\end{array}$ \\
\hline
\end{tabular}

\section{Analysis of LD muscle in Wagyu $x$ Hereford crosses versus Piedmontese $x$ Hereford crosses}

The microarray based expression profile for $\mathrm{CH} 25 \mathrm{H}$ in intact mature postnatal LD muscle is higher in Wagyu $\mathrm{x}$ Hereford crosses than Piedmontese $\mathrm{x}$ Hereford crosses by 20 months of age, the difference in expression increases with increasing developmental time and by 30 months of age is 2 fold higher (Fig. 7). This 2 fold difference very closely approximates the close to 2 fold difference in carcass IMF previously reported (8.8\% IMF in Wagyu $\mathrm{x}$ Hereford and 5.1\% IMF in Piedmontese $\mathrm{x}$ Hereford animals). The increasing significance of the observed differences at $20 \mathrm{~m}, 25 \mathrm{~m}$ and $30 \mathrm{~m}$ are reflected by $P$ values of $0.478,0.158$ and 0.003 respectively.

\section{Oxysterol metabolite quantitation}

The relationships of the oxysterols to the IMF phenotypes are documented below in Table 10 and Fig. 8. The Full SAS output to all 15 phenotypes can be found in Additional file 4.

Despite most of the phenotypes provided (8/15) being non-marbling related, at the $P<0.05$ threshold, the only phenotypes significantly associated with the various oxysterols are marbling related phenotypes (the one exception being $7 \alpha, 25$-dihydroxycholesterol and Eye Muscle Area with $\mathrm{r}=0.72, P=0.04)$. This means the non-IMF fat depot phenotypes did not reach significance with any of the quantitated oxysterols.

We have detected 4 positive correlations and 3 negative correlations. In terms of absolute correlations to IMF phenotypes, 24S-hydroxycholesterol's relationship to Eye Round IMF is the top performer $(\mathrm{r}=0.91 ; P<$
0.001) (Additional file 4). No significant relationship to loin IMF was detected for any of the oxysterols although $7 \alpha, 26-$ diHCO approached significance $(\mathrm{r}=0.67 ; P=$ 0.0646). Finally, 25-hydroxycholesterol is detected at much higher levels in cattle plasma than in human plasma, consistent with our prediction that the metabolite is largely derived from IMF and humans are essentially a zero IMF species.

\section{Discussion}

\section{Ruminant fat metabolism}

In ruminants the adipocytes are the primary lipogenic site. Consequently, we have focussed our study on the metabolic properties of the various fat depots. Within a ruminant adipocyte, a number of biochemical processes play a role in taking the basic metabolic building blocks (namely pre-formed FA, acetate, D-3 hydroxybutyrate and glucose) from the circulation and converting them into mature TAG. Using a genome-wide transcriptome approach we find evidence for coordinate downregulation of lipogenesis in IMF compared to SC in line with expectation. For example, de novo FA synthesis (FASN and $A C A C A$ 1.63-1.79 fold), FA elongation (ELOVL6 1.61 fold), desaturation (SCD 2.2 fold), supply of reducing power (G6PD, ME1 and PGD 1.33, 1.43 and 1.51 fold) and esterification (GPAM and DGAT2 1.3 to 1.82 fold) are rather consistently downregulated in IMF versus SC. However, elevated expression of MBOAT2 and AGPAT9 does complicate the picture for our understanding of esterification and glycerolipid synthesis in IMF. 


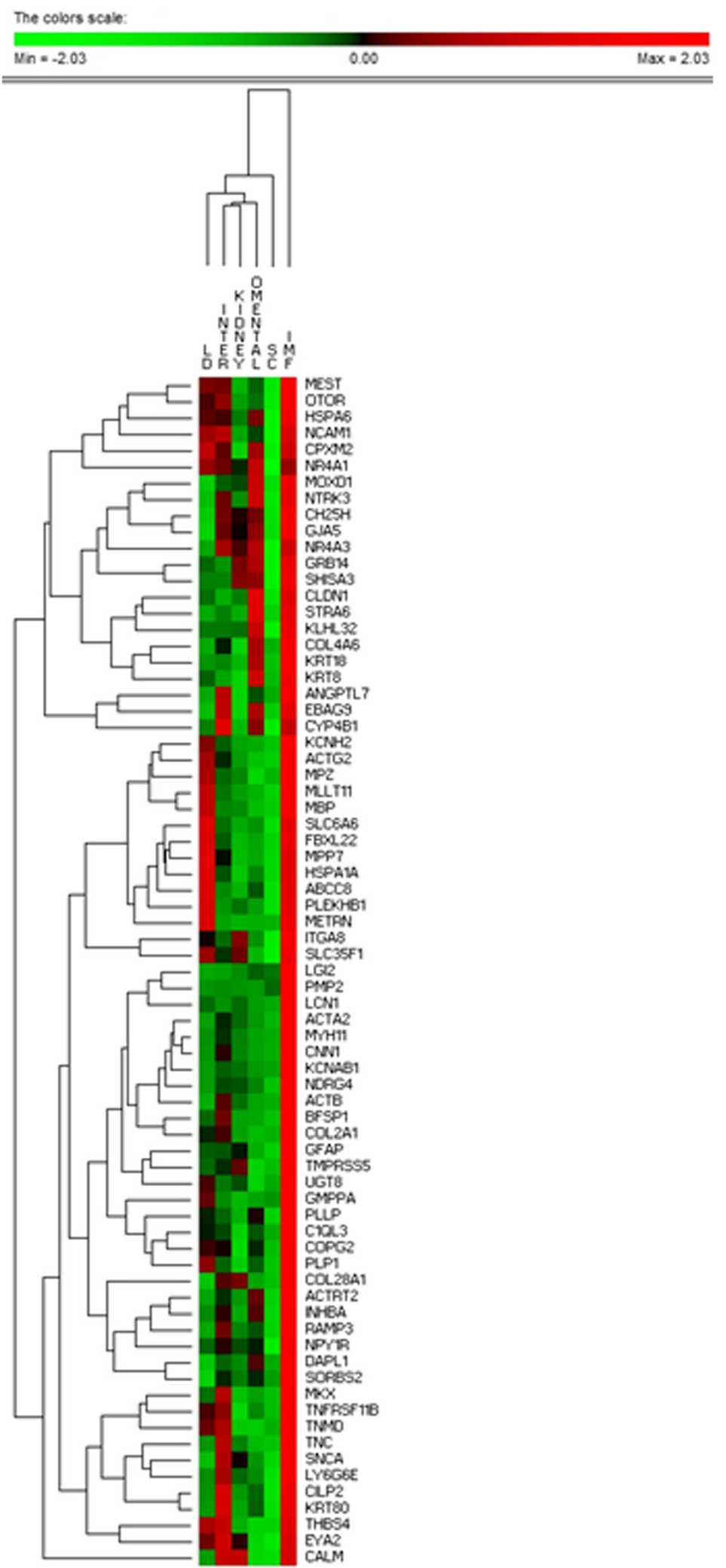

Fig. 5 (See legend on next page.) 
(See figure on previous page.)

Fig. 5 Hierarchical cluster analysis on the 73 genes whose expression suggest particular relevance to the biology of the IMF depot. This list was generated by seeking genes that satisfied two criteria, higher expression in IMF than LD by any amount, and higher expression in IMF than SC by at least 2 fold. The hierarchical clustering on tissues supports the selected gene list as being IMF diagnostic given the first branch in the tree separates the IMF samples from not only the other fat depots but the LD muscle samples too. The clustering on genes identifies positive patterns of co-expression across the treatments

In a given pathway we find that the rate limiting enzyme is sometimes among the member(s) of the pathway subject to the highest DE (e.g. FASN and $A C A C A$ in FA synthesis and ELOVL6 in elongation). Intriguingly, a number of metabolic pathways (lipolysis, pyruvate metabolism, pentose phosphate pathway) have complex patterns of up and down regulated genes between IMF and SC which are challenging to interpret. The major intracellular organelles involved in regulating this collection of lipogenic processes include the endoplasmic reticulum, the peroxisome and the mitochondria and we observe patterns of differential expression associated with all 3 organelles. For example, mitochondrial $T D H$ is strongly downregulated in IMF versus SC despite most mitochondrial mRNA for which we have data tending to be elevated in the IMF depot. TDH encodes the enzyme threonine dehydrogenase which converts the amino acid threonine into pyruvate during catabolism.

\section{All fat depots gene expression comparison}

All 5 fat depots could be clearly discriminated by the genome-wide gene expression patterns, with the fat depot variation substantially greater than any breed variation within a depot. This analysis clearly shows that at the molecular level all 5 bovine fat depots are biologically quite distinct from each other. However, it is beyond the scope of this article to discuss all depots in detail. Nevertheless, the clustering output does represent a robust quality checking metric, implying the various tissue samples have been dissected, RNA extracted, microarray hybridised and statistically normalised without any major mix-up or substantive analytic error.

IMF was awarded a separate branch from the other 4 fat depots suggesting it is by some margin the most functionally divergent. However, the presence of a small amount of LD muscle in the IMF sample but not the other fat depots cannot be ruled out as the major cause of this clustering. On this note, the muscle contamination in IMF had to be formally accounted for in subsequent analyses aimed at understanding the particular biology of IMF. Of the other 4 fat depots that we are confident contain no muscle contamination at all, SC appears to be the most functionally divergent. Plotting the MA plots of $\mathrm{SC}$ versus all the other depots in turn consistently points to high expression of HOXA10 and low expression of DLK1 in SC. Analogous gene expression observations have been made previously in the SC depots of humans and rodents and have been attributed to variable proportions of populations of pre-adipocytes $[15,16]$.

\section{IMF versus SC PART 1 Basic structural differences}

It has been previously established that marbling adipocytes are substantially smaller than SC adipocytes with peak diameters of $104 \pm 2 \mu \mathrm{m}$ and $141 \pm 5 \mu \mathrm{m}$ respectively [6]. For geometric reasons IMF samples will possess more cell membrane per cytoplasmic volume on a per unit tissue basis. This will be reflected in the total RNA

Table 5 Top 10 most downregulated genes in IMF versus SC that are probably not attributable to LD contamination (IMF expression lower than LD). All values are log2 normalised mean expression. $P$ values are reported for both DE and PIF (based on the SC versus IMF comparison)

\begin{tabular}{lllllllll}
\hline Gene & Probe & LD & IMF & SC & Inter & Kid & Omen & $P$ value (DE / PIF) \\
\hline ANGPTL4 & A_73_101924 & 14.49 & 14.41 & 15.03 & 14.77 & 14.67 & 14.89 & $0.0168 / 0.00321$ \\
IGFBP5 & A_73_110179 & 14.65 & 14.62 & 15.20 & 14.79 & 14.44 & 14.71 & $0.0223 / 0.00595$ \\
HOXA10 & A_73_104882 & 6.99 & 6.93 & 8.03 & 6.28 & 7.34 & 5.61 & $0.000265 / 0.0133$ \\
KLK9 & A_73_117770 & 8.93 & 8.44 & 9.33 & 8.39 & 8.15 & 8.18 & $0.00197 / 0.0154$ \\
BRE & A_73_P052356 & 15.27 & 15.07 & 15.56 & 14.92 & 15.00 & 15.02 & $0.0456 / 0.0216$ \\
PRSS23 & A_73_111432 & 14.05 & 14.03 & 14.53 & 14.17 & 13.75 & 14.18 & $0.0403 / 0.0166$ \\
C2CD4B & A_73_P047791 & 11.58 & 11.41 & 12.00 & 11.43 & 11.40 & 12.65 & $0.0223 / 0.0278$ \\
GPX4 & A_73_106948 & 14.42 & 14.29 & 14.76 & 14.52 & 14.62 & 14.49 & $0.0485 / 0.0291$ \\
ZCCHC12 & A_73_112381 & 14.97 & 14.57 & 15.02 & 14.26 & 14.30 & 14.43 & $0.0515 / 0.0294$ \\
FAM71A & A_73_P048226 & 4.36 & 4.18 & 5.39 & 4.65 & 5.12 & 5.99 & $0.0000769 / 0.0515$ \\
\hline
\end{tabular}


Table 6 The numerical and biological outcomes of the single criteria approach we applied to first diagnose the impact of contaminating LD muscle on the IMF samples. The background list was composed of 34,228 genes including duplicates (14,477 unique). A number of these approaches based on high expression in IMF identify the presence of contaminating LD muscle

\begin{tabular}{lll}
\hline Single Query & $\begin{array}{l}\text { Number of genes satisfying criteria } \\
\text { (in brackets duplicates removed) }\end{array}$ & $\begin{array}{l}\text { Functional enrichment for 'muscle } \\
\text { systems process' (FDR q value) }\end{array}$ \\
\hline LD $>4$ fold higher than SC & $279(171)$ & 2.04 e-39 \\
IMF $>1.32$ fold higher than the average of all fat depots & $1833(1112)$ & 3.05 e-43 \\
IMF $>1.68$ fold higher than the average of all fat depots & $741(452)$ & 4.42 e-44 \\
IMF $>2$ fold higher than SC & $600(380)$ & 1.26 e-40 \\
IMF $>1.32$ fold lower than SC & $890(581)$ & None identified. Top hit 'defense \\
& & response' 5.09 e-18 \\
IMF $>2$ fold higher than LD & $329(219)$ & $\begin{array}{l}\text { None identified. Top hit 'lipid } \\
\text { metabolic process' 2.98 e-4 }\end{array}$ \\
IMF $>$ LD by any amount & $22,156(10,679)$ & $\begin{array}{l}\text { None identified. Top hit 'cell } \\
\text { migration' } 1.51 \text { e-11 }\end{array}$ \\
IMF $<$ LD by any amount & $12,072(6839)$ & $\begin{array}{l}\text { None identified. Top hit } \\
\text { 'translational termination' 3.02 e-18 }\end{array}$ \\
\hline
\end{tabular}

used as input for transcriptomes analyses and may explain the presence of a set of membrane proteins $(M P Z$, NDRG4, RAMP3, PLP1, KCNH2) in the list of relatively upregulated genes in IMF versus SC. Adipose tissue in general is well innervated [17]. The presence of several genes highly expressed in nervous tissue $(M P Z, M B P$, METRN, PMP2, GFAP) as upregulated in IMF is consistent with the notion that the IMF depot has a modified and/or denser innervation than the SC depot. Because these findings have accounted for LD contamination, we suggest the result is unlikely to be attributed to the simple presence of motor nerves.

Furthermore, IMF appears to possess a unique cytoskeletal architecture, with the marbling adipocytes expressing substantially higher levels of a subset of cytoskeletal genes (CNN1, ACTA2, MYH11, ACTG2,
$A C T B, A C T R T 2, S O R B S 2)$. It has been known for some time that cytoskeletal architecture changes substantially during adipocyte differentiation from a structured to disorganised state [18]. In line with our data, CNN1 encoding calponin 1 was found to be upregulated in the muscle transcriptomes of high IMF Meishan compared to low IMF Landrace pigs [19], and also to be more than 2 fold upregulated in 20 month Wagyu by Hereford crosses compared to Piedmontese by Hereford crosses (data from [20]). Our analysis also suggests that IMF adipocytes are embedded in an extracellular matrix environment that is either structurally distinct (or overall more pronounced) when compared to SC, given elevated expression of these genes encoding various extracellular matrix (ECM) components (GFAP, COL28A1,

Table 7 The numerical and biological outcomes of the multiple criteria approach we applied to resolve the impact of contaminating LD muscle on the IMF samples. The background list was composed of 34,228 genes including duplicates (14,477 unique). This approach eliminates the enrichment for 'muscle systems process' indicating the impact of the contaminating LD muscle in the IMF samples has been adequately dealt with

\begin{tabular}{|c|c|c|c|}
\hline $\begin{array}{l}\text { Group Query (in brackets number of } \\
\text { genes satisfying individual criteria) }\end{array}$ & $\begin{array}{l}\text { Number of genes satisfying } \\
\text { criteria (in brackets duplicates } \\
\text { removed) / \% of total }\end{array}$ & Deviation from null expectation & $\begin{array}{l}\text { Functional enrichment for } \\
\text { 'muscle systems process' } \\
\text { (FDR q value) }\end{array}$ \\
\hline $\begin{array}{l}\text { IMF }>1.32 \text { fold higher than the average of all } \\
\text { fat depots (1833) AND IMF }>2 \text { fold higher } \\
\text { than LD (329) }\end{array}$ & $67(49) / 0.196$ & $\begin{array}{l}3.82 \text { fold enrichment compared to what } \\
\text { would be expected if the two criteria were } \\
\text { independent }\end{array}$ & $\begin{array}{l}\text { None identified. No other } \\
\text { hits at FDR } q<0.01\end{array}$ \\
\hline $\begin{array}{l}\text { IMF }>1.68 \text { fold higher than the average of all } \\
\text { fat depots }(741) \text { AND IMF }>\text { LD by any } \\
\text { amount }(22,156)\end{array}$ & $105(76) / 0.307$ & $\begin{array}{l}4.52 \text { fold depletion compared to what } \\
\text { would be expected if the two criteria were } \\
\text { independent }\end{array}$ & $\begin{array}{l}\text { None identified. No other } \\
\text { hits at FDR } q<0.01\end{array}$ \\
\hline $\begin{array}{l}\text { IMF }>2 \text { fold higher than SC (600) AND IMF }> \\
\text { LD by any amount }(22,156)\end{array}$ & $93(73) / 0.271$ & $\begin{array}{l}4.87 \text { fold depletion compared to what } \\
\text { would be expected if the two criteria were } \\
\text { independent }\end{array}$ & $\begin{array}{l}\text { None identified. No other } \\
\text { hits at FDR } q<0.01\end{array}$ \\
\hline $\begin{array}{l}\text { IMF }>1.32 \text { fold lower than SC (890) AND } \\
\text { IMF }<\text { LD by any amount }(12,072)\end{array}$ & $49(41) / 0.143$ & $\begin{array}{l}6.41 \text { depletion compared to what would } \\
\text { be expected if the two criteria were } \\
\text { independent }\end{array}$ & $\begin{array}{l}\text { None identified. No other } \\
\text { hits at FDR } q<0.01\end{array}$ \\
\hline
\end{tabular}


Table 8 Summary of the gene expression patterns of influential enzymes and other proteins in lipogenesis (all data log2 normalised mean expression). $P$ values are reported for both DE and PIF (based on the SC versus IMF comparison). Given no additional criteria have been applied here to de-emphasise the effect of LD contamination the $P$ values reported in this table do need to be interpreted cautiously. The muscle isoform of PFK (PFKM) is a case in point, as the extreme $P$ value awarded is almost certainly a consequence of LD contamination in the IMF samples

\begin{tabular}{|c|c|c|c|c|c|c|c|c|c|c|}
\hline Pathway & $\begin{array}{l}\text { Pathway flux control } \\
\text { enzymes and proteins }\end{array}$ & Gene & Probe & $\begin{array}{l}\text { Cellular } \\
\text { localisation }\end{array}$ & LD & IMF & SC & $\begin{array}{l}\text { IMF } \\
\text { Vs } \\
\text { SC } \\
\text { FC }\end{array}$ & $\begin{array}{l}\text { IMF } \\
\text { minus } \\
\text { SC } \\
(\log 2)\end{array}$ & $\begin{array}{l}P \text { value } \\
\text { (DE / PIF) }\end{array}$ \\
\hline $\begin{array}{l}\text { Glucose transport } \\
\text { into cell }\end{array}$ & $\begin{array}{l}\text { Facilitated glucose } \\
\text { transporter (not an } \\
\text { enzyme, stimulated } \\
\text { by insulin) }\end{array}$ & $\begin{array}{l}\text { SLC2A4 } \\
\text { (GLUT4) }\end{array}$ & $\begin{array}{l}\text { A_73- } \\
\text { P102656 }\end{array}$ & Membrane & 8.08 & 8.09 & 7.83 & 1.19 & 0.26 & $0.32 / 0.38$ \\
\hline \multirow[t]{12}{*}{ Glycolytic flux } & \multirow[t]{4}{*}{ Hexokinase; EC 2.7.1.1 } & $H K 1$ & $\begin{array}{l}\text { A_73- } \\
115982\end{array}$ & \multirow[t]{4}{*}{ Mitochondrion } & 13.31 & 13.90 & 14.05 & -1.10 & -0.14 & $0.23 / 0.24$ \\
\hline & & HK2 & $\begin{array}{l}\text { A_73- } \\
\text { P082146 }\end{array}$ & & 10.66 & 10.38 & 10.50 & -1.08 & -0.12 & $0.26 / 0.29$ \\
\hline & & HK3 & $\begin{array}{l}\text { A_73- } \\
109966\end{array}$ & & 6.63 & 7.24 & 7.85 & -1.53 & -0.61 & $\begin{array}{l}0.0194 / \\
0.0883\end{array}$ \\
\hline & & PFKL & $\begin{array}{l}\text { A_73- } \\
109643\end{array}$ & & 12.57 & 13.24 & 13.51 & -1.19 & -0.26 & $0.14 / 0.14$ \\
\hline & \multirow[t]{7}{*}{$\begin{array}{l}\text { Phosphofructokinase; } \\
\text { EC 2.7.1.11 }\end{array}$} & PFKM & $\begin{array}{l}\text { A_73- } \\
\text { P050301 }\end{array}$ & \multirow[t]{7}{*}{ Cytosol } & 14.87 & 14.45 & 12.38 & 4.19 & 2.07 & $\begin{array}{l}0.0000000049 \\
/ 2.68 \mathrm{e}-10\end{array}$ \\
\hline & & PFKP & $\begin{array}{l}\text { A_73- } \\
\text { P118106 }\end{array}$ & & 9.65 & 10.45 & 10.61 & -1.12 & -0.16 & $0.22 / 0.26$ \\
\hline & & PFKFB1 & $\begin{array}{l}\text { A_73- } \\
112668\end{array}$ & & 10.77 & 10.38 & 9.77 & 1.53 & 0.61 & $0.0689 / 0.10$ \\
\hline & & PFKFB2 & $\begin{array}{l}\text { A_73- } \\
109539\end{array}$ & & 8.03 & 7.75 & 7.55 & 1.15 & 0.20 & $0.38 / 0.44$ \\
\hline & & PFKFB3 & $\begin{array}{l}\text { A_73- } \\
\text { P073546 }\end{array}$ & & 11.70 & 11.55 & 11.84 & -1.22 & -0.29 & $0.12 / 0.14$ \\
\hline & & PFKFB4 & $\begin{array}{l}\text { A_73- } \\
\text { P500153 }\end{array}$ & & 15.22 & 14.81 & 13.63 & 2.27 & 1.18 & $\begin{array}{l}0.000835 / \\
0.0000537\end{array}$ \\
\hline & & PKM & $\begin{array}{l}\text { A_73- } \\
\text { P100636 }\end{array}$ & & 10.65 & 10.10 & 8.12 & 3.94 & 1.98 & $\begin{array}{l}0.000000022 / \\
0.0000145\end{array}$ \\
\hline & $\begin{array}{l}\text { Pyruvate kinase; } \\
\text { EC 2.7.1.105 }\end{array}$ & $P K L R$ & $\begin{array}{l}\text { A_73- } \\
\text { P030011 }\end{array}$ & $\begin{array}{l}\text { Cytoplasm, } \\
\text { cytosol, } \\
\text { mitochondrion }\end{array}$ & 6.28 & 6.38 & 6.17 & 1.16 & 0.21 & $0.37 / 0.46$ \\
\hline \multirow[t]{7}{*}{$\begin{array}{l}\text { Pyruvate } \\
\text { metabolism }\end{array}$} & $\begin{array}{l}\text { Pyruvate carboxylase; } \\
\text { EC 6.4.1.1 }\end{array}$ & $P C$ & $\begin{array}{l}\text { A_73- } \\
\text { P426106 }\end{array}$ & Mitochondrion & 12.09 & 12.46 & 13.20 & -1.67 & -0.74 & $\begin{array}{l}0.00723 / \\
0.00546\end{array}$ \\
\hline & \multirow[t]{4}{*}{$\begin{array}{l}\text { Pyruvate dehydrogenase } \\
\text { kinase; EC 2.7.11.2 }\end{array}$} & PDK1 & $\begin{array}{l}\text { A_73- } \\
117436\end{array}$ & Mitochondrion & 6.34 & 6.37 & 6.60 & -1.18 & -0.24 & $0.168 / 0.27$ \\
\hline & & PDK2 & $\begin{array}{l}\text { A_73- } \\
117896\end{array}$ & Mitochondrion & 14.14 & 13.87 & 13.76 & 1.08 & 0.11 & $0.48 / 0.44$ \\
\hline & & PDK3 & $\begin{array}{l}\text { A_73- } \\
114206\end{array}$ & Mitochondrion & 10.00 & 10.43 & 10.11 & 1.25 & 0.32 & $0.26 / 0.28$ \\
\hline & & PDK4 & $\begin{array}{l}\text { A_73- } \\
119171\end{array}$ & Mitochondrion & 15.02 & 14.88 & 14.41 & 1.38 & 0.47 & $0.14 / 0.0728$ \\
\hline & $\begin{array}{l}\text { Pyruvate dehydrogenase } \\
\text { phosphatase; EC 3.1.3.43 }\end{array}$ & PDP1 & $\begin{array}{l}\text { A_73- } \\
110779\end{array}$ & Mitochondrion & 6.56 & 6.34 & 5.83 & 1.43 & 0.52 & $0.11 / 0.29$ \\
\hline & $\begin{array}{l}\text { Pyruvate dehydrogenase; } \\
\text { EC 1.2.4.1 }\end{array}$ & PDHA1 & $\begin{array}{l}\text { A_73- } \\
111180\end{array}$ & Mitochondrion & 16.42 & 16.09 & 15.89 & 1.15 & 0.20 & $0.38 / 0.28$ \\
\hline $\begin{array}{l}\text { Citrate transport out } \\
\text { of mitochondria and } \\
\text { subsequent } \\
\text { conversion into } \\
\text { Acetyl CoA }\end{array}$ & $\begin{array}{l}\text { ATP citrate lyase; } \\
\text { EC 2.3.3.8 }\end{array}$ & $A C L Y$ & $\begin{array}{l}\text { A_73- } \\
111688\end{array}$ & $\begin{array}{l}\text { Cytoplasm, } \\
\text { cytosol, } \\
\text { mitochondrion }\end{array}$ & 11.32 & 11.89 & 12.12 & -1.18 & -0.24 & $0.16 / 0.17$ \\
\hline FA synthesis de & Acetyl CoA carboxylase; & ACACA & A_73_ & Cytoplasm, & 6.13 & 6.90 & 7.74 & -1.79 & -0.84 & $0.0031 / 0.042$ \\
\hline
\end{tabular}


Table 8 Summary of the gene expression patterns of influential enzymes and other proteins in lipogenesis (all data log2 normalised mean expression). $P$ values are reported for both DE and PIF (based on the SC versus IMF comparison). Given no additional criteria have been applied here to de-emphasise the effect of LD contamination the $P$ values reported in this table do need to be interpreted cautiously. The muscle isoform of PFK (PFKM) is a case in point, as the extreme $P$ value awarded is almost certainly a consequence of LD contamination in the IMF samples (Continued)

\begin{tabular}{|c|c|c|c|c|c|c|c|c|c|c|}
\hline Pathway & $\begin{array}{l}\text { Pathway flux control } \\
\text { enzymes and proteins }\end{array}$ & Gene & Probe & $\begin{array}{l}\text { Cellular } \\
\text { localisation }\end{array}$ & LD & IMF & SC & $\begin{array}{l}\text { IMF } \\
\text { VS } \\
\text { SC } \\
\text { FC }\end{array}$ & $\begin{array}{l}\text { IMF } \\
\text { minus } \\
\text { SC } \\
(\log 2)\end{array}$ & $\begin{array}{l}P \text { value } \\
\text { (DE / PIF) }\end{array}$ \\
\hline \multirow[t]{2}{*}{ novo } & EC 6.4.1.2 & & P038926 & $\begin{array}{l}\text { cytosol, } \\
\text { mitochondrion }\end{array}$ & & & & & & \\
\hline & $\begin{array}{l}\text { Fatty acid synthase; } \\
\text { EC 2.3.1.85 }\end{array}$ & FASN & $\begin{array}{l}\text { A_73_- } \\
\text { P174332 }\end{array}$ & $\begin{array}{l}\text { Golgi, } \\
\text { cytoplasm, } \\
\text { cytosol, } \\
\text { mitochondrion }\end{array}$ & 16.08 & 17.23 & 17.94 & -1.63 & -0.71 & $\begin{array}{l}0.00918 / \\
0.000528\end{array}$ \\
\hline $\begin{array}{l}\text { FA elongation to } \\
\text { C18:0 }\end{array}$ & $\begin{array}{l}\text { Fatty acid elongase 6; } \\
\text { EC 2.3.1.199 }\end{array}$ & ELOVL6 & $\begin{array}{l}\text { A_73- } \\
\text { P404726 }\end{array}$ & $\begin{array}{l}\text { Endoplasmic } \\
\text { reticuluum }\end{array}$ & 9.33 & 10.83 & 11.51 & -1.61 & -0.69 & $\begin{array}{l}0.0116 / \\
0.0175\end{array}$ \\
\hline $\begin{array}{l}\text { Desaturation to C18: } \\
1\end{array}$ & $\begin{array}{l}\text { Stearoyl-CoA desaturase (delta-9- } \\
\text { desaturase); EC 1.14.19.1 }\end{array}$ & $S C D$ & $\begin{array}{l}\text { A_73- } \\
\text { P252739 }\end{array}$ & $\begin{array}{l}\text { Endoplasmic } \\
\text { reticuluum }\end{array}$ & 14.46 & 15.33 & 16.47 & -2.20 & -1.14 & $\begin{array}{l}0.000153 / \\
0.00000163\end{array}$ \\
\hline \multirow[t]{4}{*}{$\begin{array}{l}\text { Supply of reducing } \\
\text { power }\end{array}$} & $\begin{array}{l}\text { NADP malate dehydrogenase } \\
\text { (Malic enzyme); EC 1.1.1.82 }\end{array}$ & ME1 & $\begin{array}{l}\text { A_73- } \\
118619\end{array}$ & $\begin{array}{l}\text { Cytosol, } \\
\text { mitochondrion }\end{array}$ & 11.23 & 11.50 & 12.02 & -1.43 & -0.52 & $\begin{array}{l}0.0355 / / \\
0.0427\end{array}$ \\
\hline & $\begin{array}{l}\text { Glucose-6-phosphate } \\
\text { dehydrogenase; EC 1.1.1.49 }\end{array}$ & G6PD & $\begin{array}{l}\text { A_73- } \\
\text { P168952 }\end{array}$ & $\begin{array}{l}\text { Cytoplasm, } \\
\text { cytosol }\end{array}$ & 6.28 & 7.11 & 7.52 & -1.33 & -0.41 & $0.0688 / 0.16$ \\
\hline & $\begin{array}{l}\text { Phosphogluconate } \\
\text { dehydrogenase; EC 1.1.1.44 }\end{array}$ & $P G D$ & $\begin{array}{l}\text { A_73- } \\
113428\end{array}$ & Cytosol & 14.29 & 15.04 & 15.63 & -1.51 & -0.59 & $\begin{array}{l}0.0223 / \\
0.0743\end{array}$ \\
\hline & $\begin{array}{l}\text { NADP Isocitrate dehydrogenase; } \\
\text { EC1.1.1.42 }{ }^{\mathrm{b}}\end{array}$ & IDH1 & & & & & & & & \\
\hline \multirow[t]{2}{*}{ Esterification ${ }^{c}$} & $\begin{array}{l}\text { Glycerol-3-phosphate } \\
\text { acyltransferasea; EC 2.3.1.15 }\end{array}$ & GPAM & $\begin{array}{l}\text { A_73- } \\
\text { P396821 }\end{array}$ & $\begin{array}{l}\text { Mitochondrion, } \\
\text { endoplasmic } \\
\text { reticulum }\end{array}$ & 12.97 & 13.71 & 14.09 & -1.3 & -0.38 & $\begin{array}{l}0.0811 / \\
0.0647\end{array}$ \\
\hline & $\begin{array}{l}\text { Diacylglycerol O-acyltransferase } \\
\text { 2; EC 2.3.1.20 }\end{array}$ & DGAT2 & $\begin{array}{l}\text { A_73- } \\
118582\end{array}$ & $\begin{array}{l}\text { Endoplasmic } \\
\text { reticulum, } \\
\text { cytoplasm }\end{array}$ & 14.51 & 15.86 & 16.72 & -1.82 & -0.86 & $\begin{array}{l}0.00238 / \\
0.000132\end{array}$ \\
\hline $\begin{array}{l}\text { Preformed FA from } \\
\text { blood }\end{array}$ & Lipoprotein lipase; EC 3.1.1.34 & $L P L$ & $\begin{array}{l}\text { A_73- } \\
108260\end{array}$ & $\begin{array}{l}\text { Cell surface } \\
\text { membrane }\end{array}$ & 15.27 & 16.06 & 16.35 & -1.22 & -0.29 & $0.128 / 0.0847$ \\
\hline \multirow{4}{*}{$\begin{array}{l}\text { Lipolysis } \\
\text { (triacylglycerides to } \\
\text { diacylglycerides to } \\
\text { monoglycerides) }\end{array}$} & $\begin{array}{l}\text { Hormone sensitive lipase; } \\
\text { EC 3.1.1.79 }\end{array}$ & LIPE & $\begin{array}{l}\text { A_73- } \\
101039\end{array}$ & Cytosol & 10.23 & 11.16 & 11.57 & -1.33 & -0.41 & $\begin{array}{l}0.0688 / \\
0.0861\end{array}$ \\
\hline & $\begin{array}{l}\text { Adipose triglyceride lipase; } \\
\text { EC 3.1.1.3 }\end{array}$ & PNPLA2 & $\begin{array}{l}\text { A_73- } \\
\text { P052461 }\end{array}$ & $\begin{array}{l}\text { Cytosol, } \\
\text { endoplamic } \\
\text { reticulum, } \\
\text { lipid particle }\end{array}$ & 15.61 & 15.91 & 16.30 & -1.31 & -0.39 & $\begin{array}{l}0.0768 / \\
0.0391\end{array}$ \\
\hline & $\begin{array}{l}\text { Monoglyceride lipase; } \\
\text { EC 3.1.1.23 }\end{array}$ & MGLL & $\begin{array}{l}\text { A_73- } \\
104056\end{array}$ & $\begin{array}{l}\text { Cytosol, } \\
\text { endoplasmic } \\
\text { reticuluum }\end{array}$ & 15.19 & 15.30 & 15.78 & -1.39 & -0.48 & $\begin{array}{l}0.0456 / \\
0.0203\end{array}$ \\
\hline & Perilipin & PLIN2 & $\begin{array}{l}\text { A_73- } \\
\text { P044606 }\end{array}$ & $\begin{array}{l}\text { Cytosol, } \\
\text { endoplasmic } \\
\text { reticulum, lipid } \\
\text { particle }\end{array}$ & 12.33 & 12.63 & 13.31 & -1.61 & -0.69 & $\begin{array}{l}0.0116 / \\
0.00793\end{array}$ \\
\hline Carrier proteins & $\begin{array}{l}\text { Fatty acid binding protein } 4 \\
\text { (not an enzyme, quantitative } \\
\text { impact on process not } \\
\text { known?) }\end{array}$ & FABP4 & $\begin{array}{l}\text { A_73- } \\
113342\end{array}$ & $\begin{array}{l}\text { Cytoplasm, } \\
\text { cytosol }\end{array}$ & 10.69 & 12.67 & 13.13 & -1.38 & -0.46 & $\begin{array}{l}0.0515 / / \\
0.0469\end{array}$ \\
\hline
\end{tabular}

${ }^{a}$ GPAM (alias GPAT1) a quantitatively influential enzyme of esterification according to [14]

${ }^{b}$ Cytosolic NADP isocitrate dehydrogenase (IDH1) is not registered as expressed in our fat depot mRNA data

c While not considered rate-limiting for esterification (and glycerolipid synthesis) we wish to draw attention to the expression profiles for a number of additional genes in these two pathways as some have expression profiles indicating higher activity in the IMF than the SC (that cannot be explained by LD muscle contamination) (Table 9) 
Table 9 Expression profiles of particular isoforms in esterification and glycerolipid synthesis where IMF shows higher expression than SC that is not attributable to LD contamination. Normalised mean expression values (log2) for LD muscle, dissected IMF and SC. $P$ values are reported for both DE and PIF (based on the SC versus IMF comparison). These non significant $P$ values need to be interpreted cautiously as these genes do satisfy the independent requirement of higher expression in IMF than LD which we argue makes them potentially noteworthy

\begin{tabular}{|c|c|c|c|c|c|c|c|c|c|c|}
\hline Pathway & Enzyme & Gene & Probe & $\begin{array}{l}\text { Cellular } \\
\text { localisation }\end{array}$ & LD & IMF & SC & $\begin{array}{l}\text { IMF vS } \\
\text { SC FC }\end{array}$ & $\begin{array}{l}\text { IMF minus } \\
\text { SC (log2) }\end{array}$ & $\begin{array}{l}P \text { value } \\
\text { (DE / PIF) }\end{array}$ \\
\hline Esterification & Glycerol kinase 2; EC 2.7.1.30 & GK2 & A_73_113526 & $\begin{array}{l}\text { Cytoplasm, } \\
\text { mitochondrion }\end{array}$ & 5.83 & 6.20 & 5.90 & 1.23 & 0.30 & $\begin{array}{l}0.28 / \\
0.41\end{array}$ \\
\hline Esterification & Glycerol kinase 5; EC 2.7.1.30 & GK5 & A_73_113437 & As above & 5.32 & 5.81 & 5.47 & 1.27 & 0.35 & $\begin{array}{l}0.24 / \\
0.39\end{array}$ \\
\hline Esterification & $\begin{array}{l}\text { 1-acylglycerol-3-phosphate } \\
\text { O-acyltransferase 1; EC 2.3.1.51 }\end{array}$ & AGPAT1 & A_73_110232 & $\begin{array}{l}\text { Endoplasmic } \\
\text { reticuluum }\end{array}$ & 9.67 & 10.44 & 10.03 & 1.33 & 0.42 & $\begin{array}{l}0.18 / \\
0.20\end{array}$ \\
\hline Esterification & $\begin{array}{l}\text { 1-acylglycerol-3-phosphate } \\
\text { O-acyltransferase 4; EC 2.3.1.51 }\end{array}$ & AGPAT4 & A_73_115012 & $\begin{array}{l}\text { Endoplasmic } \\
\text { reticuluum, } \\
\text { membrane }\end{array}$ & 8.07 & 8.70 & 8.47 & 1.17 & 0.23 & $\begin{array}{l}0.35 / \\
0.39\end{array}$ \\
\hline Esterification & $\begin{array}{l}\text { 1-acylglycerol-3-phosphate } \\
\text { O-acyltransferase 9; EC 2.3.1.51 }\end{array}$ & AGPAT9 & $\begin{array}{l}\text { A_73- } \\
\text { P272036 }\end{array}$ & $\begin{array}{l}\text { Endoplasmic } \\
\text { reticuluum, } \\
\text { membrane }\end{array}$ & 11.55 & 12.14 & 11.63 & 1.43 & 0.51 & $\begin{array}{l}0.11 / \\
0.10\end{array}$ \\
\hline $\begin{array}{l}\text { Glycerolipid } \\
\text { synthesis }\end{array}$ & $\begin{array}{l}\text { membrane bound O-acyltransferase } \\
\text { domain containing 1; EC 2.3.1.n6 }\end{array}$ & MBOAT1 & A_73_108662 & $\begin{array}{l}\text { Endoplasmic } \\
\text { reticuluum, } \\
\text { membrane }\end{array}$ & 8.57 & 9.56 & 9.20 & 1.28 & 0.36 & $\begin{array}{l}0.22 / \\
0.27\end{array}$ \\
\hline $\begin{array}{l}\text { Glycerolipid } \\
\text { synthesis }\end{array}$ & $\begin{array}{l}\text { membrane bound O-acyltransferase } \\
\text { domain containing } 2 \text { EC 2.3.1.n7, 2.3.1.51 }\end{array}$ & MBOAT2 & A_73_118887 & $\begin{array}{l}\text { Endoplasmic } \\
\text { reticuluum, } \\
\text { membrane }\end{array}$ & 5.23 & 5.68 & 5.14 & 1.46 & 0.55 & $\begin{array}{l}0.10 / \\
0.30\end{array}$ \\
\hline $\begin{array}{l}\text { Glycerolipid } \\
\text { synthesis }\end{array}$ & Acylglycerol kinase; EC 2.7.1.107, 2.7.1.94 & $A G K$ & A_73_102007 & Mitochondrion & 4.28 & 4.58 & 4.26 & 1.25 & 0.32 & $\begin{array}{l}0.26 / \\
0.45\end{array}$ \\
\hline
\end{tabular}

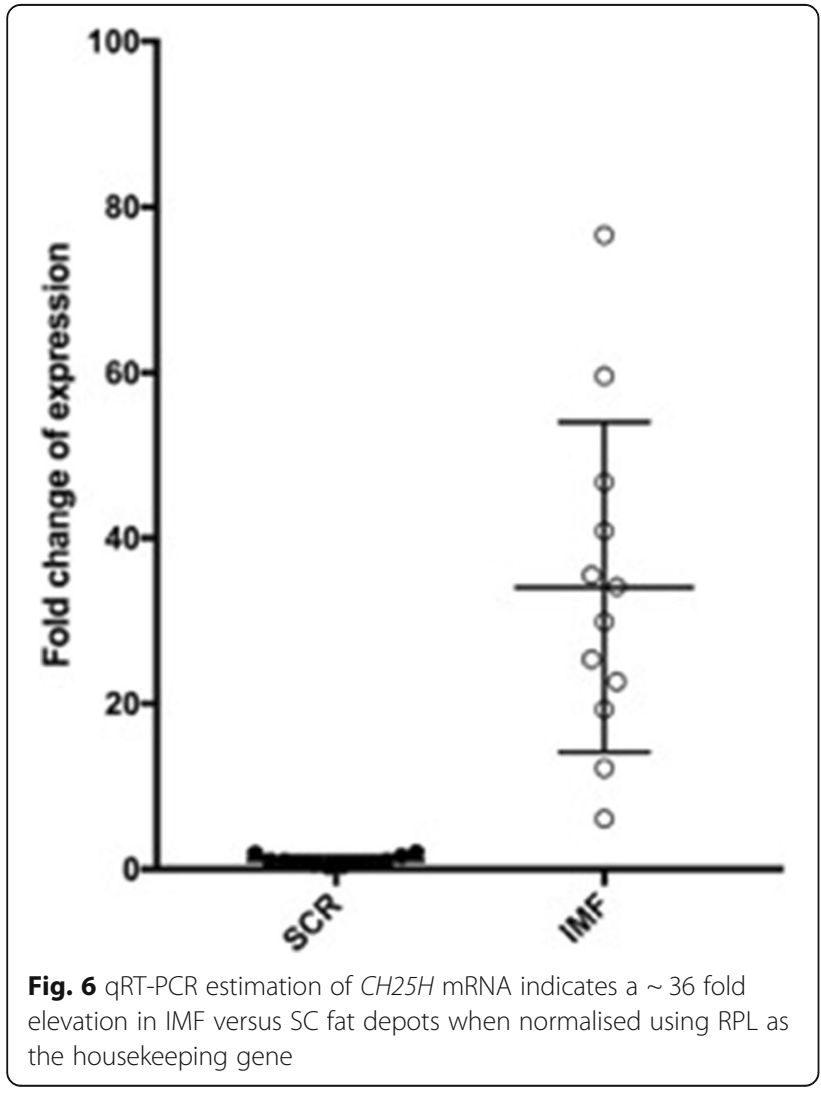

COL2A1, ITGA8, TNC, SNCA, MYH11, MKX, COL4A6 and TNFRSF11B).

An additional functional group that appears diagnostic of the IMF depot includes a subset of solute transporters (SLC6A6 and SLC3SF1). From a biomarker perspective we have also identified several genes elevated in IMF that encode proteins that have been connected to human obesity and potentially could be detectable in the plasma; these include INHBA and ANGPTL7.

\section{IMF versus SC part II metabolic biochemistry}

It is believed $\mathrm{SC}$ adipocytes contain lower levels of saturated fats, such as stearic acid (C18:0), than do IMF adipocytes [7]. Prior work profiling bovine fatty acids by gas chromatography and corresponding calculations of desaturase indices are broadly consistent with IMF expressing 2.4 fold less $S C D$ (encoding the $\triangle 9$ desaturase enzyme) in the present data. Furthermore, marbling fat has been shown in vitro to have a relative preference for glucose versus acetate carbon for de novo FA synthesis compared to SC as measured by radioisotope incorporation into bovine adipose tissue slices [6]. In that study glucose was found to be the primary precursor in IMF (51-76\%), whereas acetate was dominant in SC (67$77 \%)$. In our present data we note that ACSS2 encoding acetyl coenzyme A synthetase was expressed at $\sim 2$ fold 


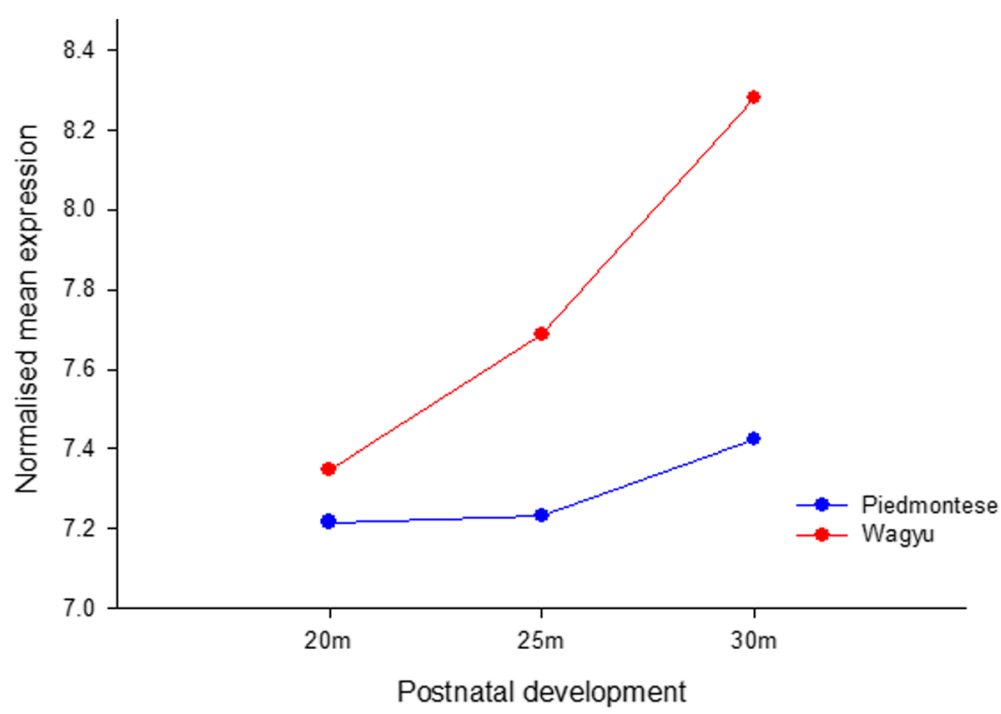

Fig. 7 Microarray expression of $\mathrm{CH} 25 \mathrm{H}$ in postnatal LD muscle increases more rapidly in Wagyu $x$ Hereford animals than Piedmontese $x$ Hereford animals and culminates in a $\sim 2$ fold difference at 30 months. This $\sim 2$ fold difference mirrors the observed $\sim 2$ fold difference in final IMF observed at the anatomical level

higher levels in SC than IMF consistent with a relative preference for acetate in the SC depot.

Furthermore, we wish to point out that NR4A3 (alias NOR1) encoding a nuclear hormone receptor in the steroid-thyroid hormone retinoid superfamily was upregulated more than 2 fold in IMF compared to SC. This transcription factor has been found to augment insulin's ability to stimulate glucose transport in rodent $3 \mathrm{~T} 3-\mathrm{L} 1$ adipocytes [21]. In fact, $N R 4 A 3$ was one of several genes identified that indicate substantive differences in carbohydrate (GRB14, NR4A3, MOXD1), retinoic acid (STRA6, MEST) and cholesterol (PMP2, CH25H, $C Y P 4 B 1)$ metabolism when comparing IMF to SC.

Malic enzyme (ME1) and ATP citrate lyase (ACLY), both presumed missing or unimportant in ruminant adipose tissue based on enzymatic analyses under standard

Table 10 Significant correlations at the $P<0.05$ threshold. Metabolite 7 is also significantly correlated with eye muscle area $(0.72$, 0.04), the only non-marbling fat association we could detect in comparing all oxysterol metabolites to all carcass phenotypes

\begin{tabular}{|c|c|c|c|c|c|c|c|c|}
\hline $\mathrm{ID}$ & $\begin{array}{l}\text { Oxysterol systematic name (abbreviation, } \\
\text { systematic name) }\end{array}$ & Biceps IMF & Chuck IMF & Eye Round IMF & Loin IMF & Oyster IMF & MSA MB & AUS MB \\
\hline Metabolite 1 & $\begin{array}{l}\text { 24S-Hydroxycholesterol (24S-HC, } \\
\text { Cholest-5-ene-3 } \beta, 24 S \text {-diol) }\end{array}$ & & & $0.91,0.001$ & & $0.84,0.008$ & & \\
\hline Metabolite 2 & $\begin{array}{l}\text { 25-Hydroxycholesterol ( } 25-\mathrm{HC} \text {, } \\
\text { Cholest-5-ene-3ß,25-diol) }\end{array}$ & & & & & & & \\
\hline Metabolite 3 & $\begin{array}{l}\text { (25R)26-Hydroxycholesterol } \\
\text { (26-HC, Cholest-5-en-3 } \beta,(25 R) 26-\text { diol) }\end{array}$ & & $-0.83,0.010$ & & & & & \\
\hline Metabolite 4 & $\begin{array}{l}\text { 7-Oxocholesterol (7-OC, } \\
\text { 3ß-Hydroxycholest-5-en-7-one) }\end{array}$ & & $-0.73,0.039$ & & & & & \\
\hline Metabolite 5 & 7a-Hydroxycholest-4-en-3-one (7a-HCO) & & & & & & $0.71,0.049$ & \\
\hline Metabolite 6 & $\begin{array}{l}\text { 7a-Hydroxycholesterol } \\
\text { (7a-HC, Cholest-5-en-3ß,7a-diol) }\end{array}$ & & & & & & & \\
\hline Metabolite 7 & $\begin{array}{l}\text { 7a,25-Dihydroxycholest-4-en-3-one } \\
\text { (7a,25-diHCO) }\end{array}$ & & & & & & & $-0.74,0.032$ \\
\hline Metabolite 8 & $\begin{array}{l}\text { 7a,25-Dihydroxycholesterol } \\
\text { (7a,25-diHC, Cholest-5-ene-3ß,7a,25-triol) }\end{array}$ & $0.71,0.049$ & & & & & & \\
\hline Metabolite 9 & $\begin{array}{l}\text { 7a,26-Dihydroxycholest-4-en-3-one } \\
\text { (7a,26-diHCO) }\end{array}$ & & & & & & & \\
\hline Metabolite 10 & $\begin{array}{l}\text { 7a,26-Dihydroxycholesterol (7a,26-diHC, } \\
\text { Cholest-5-ene-3ß,7a,26-triol) }\end{array}$ & & & & & & & \\
\hline
\end{tabular}




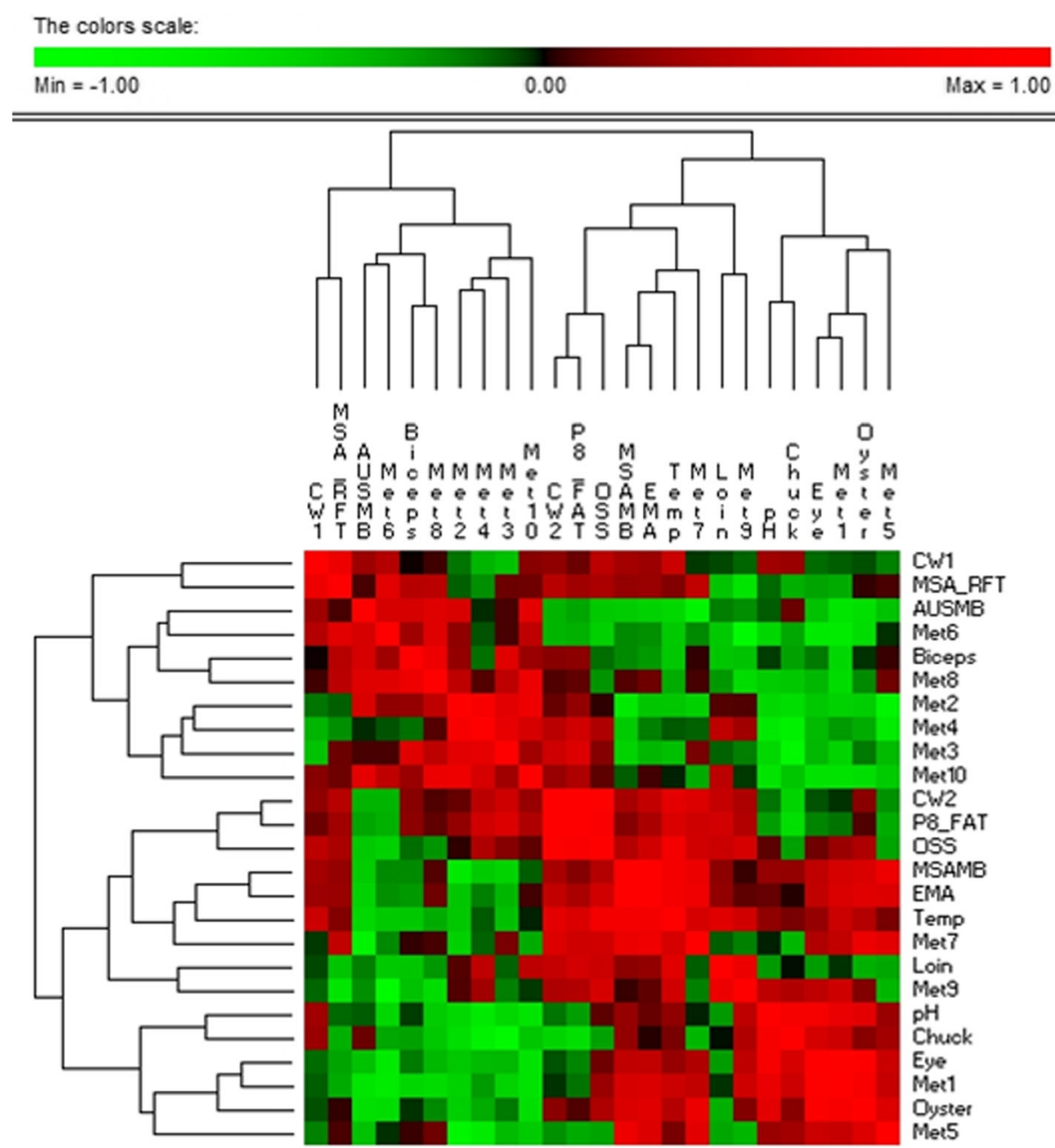

Fig. 8 Hierarchical clustering of phenotypes and oxysterol metabolites. This approach clusters (correlations of correlations) on positive relationships only. The metabolite with the tightest positive cluster to a phenotype is metabolite 1 (24S-HC) and eye round IMF $(0.91 ; P<0.001)$. While $25-\mathrm{HC}$ is not significantly associated with any phenotype, $25-\mathrm{HC}$ does cluster with the metabolites $26-\mathrm{HC}$ and $7-\mathrm{OC}$ which are in turn both correlated with chuck IMF. The key connecting metabolite number to metabolite name is documented in Table 10

metabolic conditions [22] are apparently reasonably highly expressed in these samples at the messenger RNA level. Surprisingly, we did not detect cytoplasmic NADPisocitrate dehydrogenase (IDH1) mRNA in our data, which has previously been shown to be important lipogenic player in both depots, and particularly in SC [6].

\section{IMF versus SC PART III CH25H and the 25 hydroxylation of cholesterol}

A qRT-PCR assay for $\mathrm{CH} 25 \mathrm{H}$ yielded a 34-fold higher expression in IMF than SC. $\mathrm{CH} 25 \mathrm{H}$ encodes the enzyme cholesterol 25 hydroxylase which converts cholesterol into the metabolite 25 hydroxycholesterol $(25-\mathrm{HC})$. This metabolite has never previously been linked to marbling fat specifically but is certainly known as a potent regulator of cholesterol metabolism [23, 24], fibroblastmediated tissue remodelling [25] and inflammation [26] all of which have been considered relevant to adiposity in various biological circumstances [27-29].

The tissue specific gene expression profile of $\mathrm{CH} 25 \mathrm{H}$ in humans favours soft tissue (which includes adipose tissue) according to the TiGER gene expression database [30] supporting the possibility that adipose tissue may have a disproportionate influence over the systemic expression of this enzyme and its products. The identification of $\mathrm{CH} 25 \mathrm{H}$ as an enzyme of interest prompted us to re-examine a published time course experiment where intact bovine LD muscle had been sampled in low marbling Piedmontese $\mathrm{x}$ Hereford breed crosses versus high marbling Wagyu x Hereford breed crosses over development [20].

Interestingly, between 20 and 30 months when IMF is accumulating most rapidly the $\mathrm{CH} 25 \mathrm{H}$ expression profile in the Wagyu sired cattle increases at a faster rate than 
the Piedmontese sired cattle, and ends up $\sim 2$ fold higher. This final expression difference almost exactly mirrors the close to 2 fold difference in actual IMF content observed between the breed crosses, $8.8 \%$ in Wagyu sired animals versus $5.1 \%$ in Piedmontese sired animals [31]. In other mammalian species, oxysterols have been shown to be present at detectable levels in the circulation using mass spectrometry approaches. Consequently we became interested in the possibility that circulating oxysterols such as $25-\mathrm{HC}$ might be a) detectable in cattle plasma and b) reflect carcass-wide marbling.

\section{LC-MS estimation of oxysterol metabolites}

To test our hypothesis regarding a potential link between circulating oxysterols and carcass-wide marbling we identified 8 animals displaying variation in IMF for whom we had fresh frozen plasma samples. LC-MS estimation of the 10 oxysterols using the methods of [32] was correlated to 15 carcass phenotypes (of which 7 were IMF related). Intriguingly, we found significant associations at the $P<0.05$ significance threshold for 5 oxysterols to 8 carcass phenotypes, and 7 of those 8 phenotypes were IMF related. This implies that, despite the relatively small sample size, the IMF correlations we have detected are unlikely to be false positives. It appears that circulating oxysterols could form the basis of a diagnostic blood test for IMF content. Such a test could in principle help enable a decision on whether or not to invest in expensive feedlotting.

\section{Conclusions}

We have characterised gene expression patterns discriminating bovine fat depots with a particular focus on IMF versus $\mathrm{SC}$. We found the expression patterns were suggestive of a number of observations previously made using traditional biochemical techniques, notably a generalised reduction in lipogenic activity and an apparent preference for glucose carbon in the IMF depot. A number of new discoveries were made, including expression changes consistent with coordinate modifications in the manner IMF handles cholesterol, retinoic acid and carbohydrate metabolism compared to the other depots. These gene expression signals would have remained hidden from view if we had not corrected for the presence of a small amount of muscle in the dissected IMF, and this correction was in turn made possible only by collective normalisation of the fat depot data with the LD muscle data. Of particular interest was an indication of very elevated activity of the cholesterol 25 hydroxylase enzyme in the IMF depot. A suite of oxysterol metabolites were quantitated in plasma using mass spectrometry and appear to be promising circulating biomarkers for whole carcass IMF content.

\section{Methods}

Beef cooperative research Centre III marbling and fat distribution experiment

The basic experimental details relating to this animal trial have been previously reported [12]. In brief we studied 15 individual 259 day grain fed Angus, Hereford and Wagyu $\mathrm{x}$ Angus steers ( $n=5$ per breed) slaughtered at $\sim 26$ months of age as part of the larger experiment detailed by [12]. Management was standardised for all individuals during growth on pasture from weaning through long-feedlotting. For the transcriptome analysis of the fat depots we focussed on animals' pasture-fed only during the immediate post-weaning period, rather than animals that received supplement during the immediate post-weaning period [12].

A total of 10 sires were represented across the 15 individuals, with 3 sires per genotype and only 1 or 2 individuals per sire. Fat depot samples were dissected from each carcass as soon as possible after slaughter. Dissected IMF was derived from the $M$. longissimus dorsi (IMF), with other fat samples derived from intermuscular fat (Inter), omental fat (Omen), kidney fat (Kid) and SC (over the rump) depots. The longissimus dorsi muscle with IMF in situ (LD) was also sampled. Further LD samples were also included in our analysis from animals slaughtered at an earlier time point (kill 2) representing both supplement fed and pasture fed animals. For this transcriptome analysis of the fat depots per se we focussed on animals pasture-fed only during the immediate post-weaning period.

\section{RNA extraction, microarray hybridisation and normalisation}

Total RNA was phenol chloroform extracted using Trizol (Invitrogen) following the manufacturer's instructions. RNA yield and purity were determined using spectrophotometry and RNA integrity was determined by agarose gel electrophoresis. For each breed by depot comparison 4 of the potential 5 RNA samples were prioritised for microarray hybridisation on the basis of RNA integrity and purity. The RNA was submitted to the Ramaciotti Institute (Randwick, NSW, Australia) for hybridisation to the $4 \times 44 \mathrm{~K}$ one colour Agilent bovine array. Data was normalised using a previously described mixed model approach [33] and all data in all samples expressed as $\log 2$ values (Additional file 2). Given the hybridisation to the microarray is performed based on a given total amount of input RNA, the expression measurements reported effectively represent mRNA abundance on a per unit total RNA basis. All the normalised gene expression data is publicly available via accession GSE136981 and allows for the recreation of our chosen plots and analyses. 


\section{Hypothesis-free screen}

Data driven hierarchical clustering As part of a quality checking procedure and to gain a high level view of the across tissue relationships, the expression profiles of 10 , 000 genes chosen at random were imported into PermutMatrix [34] for across-depot cluster analysis, with each breed by depot group being represented (with 4 individual animals used to produce the mean breed by depot values) (Fig. 1). With a large number of rows performance is very slow. This random 10,000 can be considered representative of the full genome-wide data. Figure labels are built from concatenating breed and tissue. Although we only used pasture fed animals from kill 5 for the fat depots gene expression, the LD muscle samples we included here are derived from a combination of pasture and supplement fed animals and 2 different kills. Given this, we included the diet and kill information in the figure labels for completeness. Global relationships between depots based on the molecular data were then determined using unsupervised hierarchical clustering performed on columns for all tissues. LD muscle was included in this analysis as an outgroup.

\section{Differential expression (DE) analysis SC versus the other fat depots}

For the next set of analyses to contrast the depots we first combined the (breed) data within each depot. This meant each depot value is the mean average of 12 individual samples ( $n=4$ for each of the 3 breeds). Two statistical strategies were used to identify differential expression between IMF and SC. First, we used a standard $t$ test for the differences in means assuming equal variances (Additional file 5). Secondly, we used z scores from a modified DE (PIF) that we processed through an inverse normal distribution to obtain 1 tailed $P$ values (Additional file 6). In terms of visualisation of the data, all fat depots were contrasted for differential expression (DE) against SC, expressed in the form of Minus Average (MA) rocket plots (Fig. 2). For the remainder of the analyses we mainly focussed on the specific comparison between SC and IMF.

\section{IMF versus $\mathbf{S C}$}

We quantitated the cellular basis of an anomaly (the atypical triangular shaped protuberance) in the structure of the IMF versus SC MA plot. This was achieved by querying the data using the "=AND" function in Microsoft Excel. We asked for all genes that satisfy the following criteria to be returned: expression $>4$ fold higher in LD muscle than in SC. We then visually highlighted those genes (i.e highly expressed in LD versus SC) on the IMF versus SC plot (Fig. 3a). The SC fat depot can be considered representative of a clean (i.e. muscle free) sample.
In order to perform function enrichment analysis we computed a modified DE (called Phenotypic Impact Factor or PIF) which we have previously found to account for the distribution of $\mathrm{DE}$ with different abundances. This approach is analogous to binning the data by abundance and prioritising the extreme $\mathrm{DE}$ within each bin. We view this as attractive because ranking on simple DE runs the risk of prioritising those mRNA that are lowly abundant and near the detection limit of the microarray platform, which is likely the noisy part of the data distribution. PIF is calculated by multiplying the DE by the average abundance across the treatment of interest [35]. After ranking on PIF one can identify the extreme 1\% (145 / 14,476) or $5 \%(724 / 14,476)$ which can then be submitted for hypergeometric functional enrichment.

\section{Mitoproteome}

Next, we aimed to establish whether there was a major intracellular composition change in terms of adipocyte mitochondrial content. To achieve this we downloaded the human mitochondrial proteome (http://mitominer. mrc-mbu.cam.ac.uk/release-3.1/begin.do) and after filtering for duplicates generated a unique list of $1045 \mathrm{nu}-$ clear and mitochondrially-encoded genes which encode all known mitochondrial proteins. The derivation of this list of mRNA encoding mitochondrial proteins and its use in a similar biological context has been previously described [36]. We overlaid these mitoproteome genes onto the IMF versus SC MA plot and also estimated the deviation from null equilibrium (i.e. to what extent is the mass of the mRNA expression data skewed upwards or downwards with respect to 0 ) as a proxy for overall mitochondrial content / activity using the method of binomial distance.

Structural differences between marbling adipocytes and the other fat depot adipocytes

In a further attempt to analyse (and also better visualise) the effect of contaminating LD on the dissected IMF gene expression we overlaid the IMF versus SC MA plot with a continuous colour spectrum reflecting genes that are most likely arising from the IMF adipocytes per se and not the contaminating LD muscle. This colour coding was achieved in an objective numerical manner by mapping a continuous colour spectrum to the DE calculated between the intact LD muscle (representing expression from mainly muscle cells) and the dissected IMF samples (reflecting expression from mainly marbling fat cells). This means that on the $\mathrm{Y}$ axis (DE) of the MA plot those values above 0 that are coloured yellow / red (higher expression in IMF than LD, as well as higher expression in IMF than SC) and those values below 0 that are coloured purple can be confidently ascribed to gene expression arising from the IMF adipocytes themselves. 
In a related set of quantitative criteria based analyses aimed at highlighting IMF expression derived from marbling adipocytes and not contaminating muscle cells, we queried the full data set for those genes whose expression satisfied at least one of two criteria: higher expression in IMF than LD muscle and higher expression in IMF than the other depots. There is no standardised approach in the literature for handling the contamination problem identified here. The exact thresholds used in our case were developed empirically through an exploratory, iterative process.

We systematically explored a number of thresholds and observed which ones produced short, manageable gene lists functionally in line with existing biological knowledge. This particular process yields thresholds that are not formal but we wish to emphasise that the numerical decisions we settled on are a) made across the board and are thus transparent and fair b) reproducible from the original data c) are entirely pragmatic - they serve our stated purpose of eradicating those genes whose expression in IMF is likely derived from the contaminating muscle signal and d) hypergeometric analysis of the target list can then be calculated with respect to the background (whole genome) gene list using the GOrilla webtool.

The multiple criteria queries were performed in Microsoft Excel using the "=AND" function. The 4 queries we have reported were generated as follows: 1) identify genes likely expressed from myocytes not adipocytes (expression in LD muscle > 4 fold higher than SC); 2) identify genes diagnostic of IMF adipocytes compared to all the other fat depots 1 (expression in IMF $>2$ fold higher than LD and expression in IMF $>1.32$ fold higher than the average expression in the other 4 fat depots); 3) identify genes diagnostic of IMF adipocytes compared to all the other fat depots 2 (expression in IMF > LD by any amount and expression in IMF $>1.68$ fold higher than the average expression in the other 4 fat depots); 4) identify genes diagnostic of IMF adipocytes compared to SC specifically (expression in IMF $>$ LD by any amount and expression in IMF is $>2$ fold higher than in SC).

The output from the last of these queries (higher expression in IMF than LD, at least 2 fold higher expression in IMF than SC) was used as input for hierarchical cluster analysis in Permut matrix following production of a tab delimited .txt file with as many rows as genes and as many columns as tissues.

Finally, we also identified those genes more lowly expressed in IMF than SC (and probably not derived from the LD contamination) as follows: expression in IMF $<$ LD by any amount and $<$ SC by at least 0.4 units).

\section{Hypothesis-driven analysis}

Lipogenesis in adipocytes Canonical KEGG pathways (https://www.genome.jp/kegg/pathway.html) were used to define lipogenic genes of interest selecting the Bos taurus pathway in all cases. For the purposes of this analysis we developed criteria to retrieve one value per gene as most genes in the microarray platform are represented by more than 1 probe. In many cases the probes show a general agreement in direction and magnitude of change, but this is not always the case. In an attempt to generate a single value per gene we decided to prioritise using the Phenotypic Impact Factor (PIF) metric. PIF is computed by multiplying $\mathrm{DE}$ by abundance. It has a number of appealing characteristics, both numerical such as tracking the distribution of the MA plots and de-emphasising noisy rarely expressed transcripts - and biological, such as clearly identifying gross myofibre composition changes when comparing skeletal muscle samples [35]. This prioritisation produces a file containing unique values for 14,476 genes (Additional file 7). The Bos taurus KGML files for "Fatty acid synthesis" (BTA00061), "Fatty acid degradation" (BTA00071), "Adipocyte lipolysis" (BTA04923) "Fatty acid elongation" (BTA00061), "Glycerolipid metabolism" (BTA00561), "Pyruvate metabolism" (BTA00620) and "Pentose phosphate metabolism" (BTA00030) were used as a resource to help us identify the mRNA encoding the relevant proteins in each biochemical pathway.

In an effort to further explore the mRNA associated with canonical pathways relevant to ruminant fat metabolism, a number of lipogenic and lipolytic pathways were identified through literature searches in NCBI Pubmed. The component enzymes and genes of the key pathways were then identified through the KEGG pathway database (http://www.genome.jp/kegg/pathway.html) using Bos taurus as the species. Further targeted literature searches were also used to determine which enzymes and other proteins could be considered influential in overall pathway flux, including the rate-limiting enzymes.

\section{qRT-PCR}

We designed 2 sets of primers for $\mathrm{CH} 25 \mathrm{H}$ (target gene) and 1 set for RPLPO (housekeeper) using Primer 3 and accepting the default settings but forcing the amplicon to be $150-250 \mathrm{bp}$ long. The first primer sequences for $\mathrm{CH} 25 \mathrm{H}$ were forward ttcagtcgcccttcttcct and reverse gtcatggggaacacgaacac. The second primer sequences for $\mathrm{CH} 25 \mathrm{H}$ were gcaccatcagaattcgtccand agccagatgttgacaacgtg. For RPLPO the sequences were forward caaccctgaagtgcttgacat and reverse aggcagatggatcagcca. These primer pairs produce amplicons of $208 \mathrm{bp}, 153 \mathrm{bp}$ and 227 bp respectively. cDNA from IMF and SC was made 
from total RNA using Superscript III following the manufacturer's instructions. Primers were first tested by conventional PCR then estimating product size on a $1.6 \%$ agarose gel. qRT-PCR was performed on an Applied Biosystems machine using Sybr Green fluorescence chemistry in $10 \mathrm{ul}$ total reaction volumes. No template controls were included on the reaction plate. 12 individual cDNA samples were quantitated for each of the two tissues of interest i.e. IMF and for SC.

\section{Analysis of LD muscle gene expression in Wagyu $x$ Hereford versus Piedmontese $x$ Hereford crosses}

We made use of a previously published microarray experiment where LD muscle had been sampled across pre and postnatal development in two breed crosses, one with higher IMF and one with lower IMF and higher muscle mass [20, 35]. The normalised mean expression values for the last 3 postnatal time points $(20$ months, 25 months and 30 months) were retrieved from the data and the expression profiles for $\mathrm{CH} 25 \mathrm{H}$ plotted for the breed crosses.

\section{Oxysterol metabolite quantitation}

Fresh frozen plasma samples from 8 cattle divergent in IMF (Additional file 8) were subject to LC-MS quantitation of a set of oxysterols as previously described [32]. The following oxysterols were detected and quantitated, 24S-hydroxycholesterol (24S-HC), 25-hydroxycholesterol (25-HC), (25R)26-hydroxycholesterol (26-HC), 7oxocholesterol (7-OC), 7 $\alpha$-hydroxycholest-4-en-3-one (7 $\alpha$-HCO), $7 \alpha$-hydroxycholesterol $(7 \alpha-\mathrm{HC}), 7 \alpha, 25$-dihy-

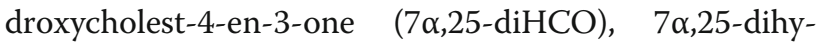
droxycholesterol (7 $\alpha, 25$-diHC), $7 \alpha, 26$-dihydroxycholest4-en-3-one (7 $\alpha, 26$-diHCO), 7 $\alpha, 26$-dihydroxycholesterol (7 $\alpha, 26-$ diHC) (Additional file 9). 25-Hydroxycholesterol is the predicted product of the 25 hydroxylase enzyme encoded by $\mathrm{CH} 25 \mathrm{H}$. The oxysterol values were then related to 15 cattle phenotypes for each animal using a correlation analysis performed in SAS.

The 15 phenotypes we assessed can be categorised as follows: 7 are marbling related (Meat Standards Australia Marbling Score $=$ MSA, AUSMARBLE Score $=$ AUS MB, Biceps femoris IMF\%, Loin IMF\%, Chuck tender IMF\%, Eye round IMF\%, Oyster blade IMF\%) and 8 are non-marbling related. The 8 non marbling related phenotypes can be further broken down as follows: 3 are muscle mass related (LD eye muscle area $=\mathrm{EMA}$, Carcass weight derived from hot sides $=\mathrm{W} 1$ and cold sides $=$ CW2), 2 are non-IMF Fat related (Rump SC fat depth $=\mathrm{P} 8$, rib fat depth $=\mathrm{RFT}$ ), 2 are meat quality related (temperature at $\mathrm{pH} 6=\mathrm{TEMP}$, ultimate $\mathrm{pH}=\mathrm{pH}$ ) and 1 reflects physiological maturity through assessment of bone development (ossification score = OSS).
Statistical analyses The microarray data were normalised using a mixed model approach as previously described [33]. We used a number of complementary methods to assess significance of differential expression. Genome-wide patterns of DE between IMF and SC were assigned significance based on two approaches: firstly, $\mathrm{DE}$ was assessed using a standard $t$ test assuming equal variances; secondly, a modified DE called PIF (Phenotypic Impact Factor) was z score transformed then those $\mathrm{z}$ scores were processed through an inverse normal distribution to obtain 1 tailed $P$ values. For the hypothesisfree genome-wide screens we ranked the entire gene lists using criteria of a modified DE (Phenotypic Impact Factor or PIF) which after ranking can then be assessed for functional gene set enrichment using hyper-geometric statistics reported as FDR corrected q values.

We used GOrilla software to perform all the functional enrichments [37, 38]. When using the two list approach in GOrilla, we established a target list using a nominal threshold (extreme 1\% or 5\%) and used a background list taken from the entire genome-wide data. We also used multiple criteria thresholding to generate target gene lists that satisfied strict requirements such they were unlikely to be derived from muscle contaminating the IMF samples and then independently assessed functional enrichment using GOrilla. The estimate of deviation from equilibrium of the cohort of mRNA encoding the mitoproteome was performed in Excel using the BINOM.DIST function. The oxysterol metabolite quantities were related to 15 cattle phenotypes for each animal using a correlation analysis performed in SAS with a $P<0.05$ considered statistically significant. The qRT-PCR data was analysed using a 2-tailed Mann Whitney U test.

\section{Supplementary information}

Supplementary information accompanies this paper at https://doi.org/10. 1186/s12864-020-6505-4

Additional file 1. A multitab Excel spreadsheet containing the lists of genes satisfying sets of criteria indicative of their likely cell type (e.g. IMF adipocyte) of origin.

Additional file 2. A CSV file containing the log 2 normalised mean expression for all 96 individual tissue samples (3 genotypes, 2 diets for intact LD muscle only, 6 tissues and 4 individual replicates per treatment cell) used in this analysis. (CSV $25668 \mathrm{~kb}$ )

Additional file 3. A word document containing two supplemental tables of gene expression patterns in two pathways (Fatty acid biosynthesis and Fatty acid elongation) relevant to lipogenesis.

Additional file 4. An HTM file containing the SAS correlation output for the metabolites and carcass phenotypes. (HTM $232 \mathrm{~kb}$ )

Additional file 5. The genome-wide $P$ values associated with differentia expression between the IMF versus SC depots. Significance was established using t tests assuming equal variance.

Additional file 6. The genome-wide $P$ values associated with the Phenotypic Impact Factor (PIF) values computed for the IMF versus SC 
depots. Significance was established from z scores processed through an inverse normal distribution to produce 1 tailed $P$ values.

Additional file 7. An excel spreadsheet containing the Minus and Average (MA) data to recreate the IMF versus SC MA plot, with values for 14,476 probes (one probe per gene). The extreme 1 and $5 \%$ by PIF are also listed here.

Additional file 8. The carcass phenotypes for those animals whose plasma was quantitated for oxysterols.

Additional file 9. The oxysterol quantitation data for the 8 selected animals.

\section{Abbreviations}

AUS MB: AUSMARBLE Score; DE: Differential expression; ECM: Extracellular matrix; IMF: Intramuscular fat; Inter: Intermuscular fat; Kid: Kidney fat; LCMS: Liquid chromatography-mass spectrometry; LD: Longissimus dorsi; MA: Minus average; MSA MB: Meat Standards Australia marbling score; Omen: Omental fat; PIF: Phenotypic Impact Factor; SC: Subcutaneous fat

\section{Acknowledgments}

The authors wish to acknowledge the support of the Beef Cooperative Research Centre without whom multi-disciplinary animal experiments on this scale may not have been possible.

\section{Authors' contributions}

$\mathrm{NH}$ project managed the gene expression component of this research, collected tissue samples, extracted the RNA, designed the GPCR primers, analysed and interpreted the data and drafted the manuscript. AR led the numerical analysis of the data including, but not limited to, normalisation of the microarray data and generation of the heat maps. WG, YW and EY analysed and interpreted mass spectrometry data. AJ performed and analysed the qRT-PCR estimation of $\mathrm{CH} 25 \mathrm{H}$. SM annotated the microarray platform and organised the submission of the transcriptome data to GEO. PG project managed the animal experiment upon which the gene expression component was based, collected tissue samples and biologically interpreted the data. DP project managed the animal experiment upon which the gene expression component was based and biologically interpreted the data. All authors read and approved the final manuscript.

\section{Funding}

This research was supported by Beef Cooperative Research Centre III. The funding body had a role in the animal experiment design and the selection of tissues for RNA analysis. Studies in Swansea were supported by the UK Biotechnology and Biological Sciences Research Council (BBSRC, grant numbers BB/N015932/1 and BB/1001735/1 to WJG, BB/L001942/1 to YW). The plasma samples were shipped to the University of Swansea using University of Queensland funds. The funders had no role in biological interpretation of the data nor in the manuscript writing.

\section{Availability of data and materials}

The datasets generated and / or analysed during the current study are publicly available in the Gene Expression Omnibus (GEO) (accession number GSE136981). The normalised mean expression data for all samples can be found in Additional file 2 and allow for the recreation of all plots and analyses.

\section{Ethics approval and consent to participate}

Use of animals and the procedures performed in this study were approved by the New South Wales (NSW) Department of Primary Industries Orange Agricultural Institute Animal Ethics Committee (approval number ORA 08/ 005).

\section{Consent for publication}

Not applicable.

\section{Competing interests}

The authors declare that they have no competing interests.

\section{Author details}

${ }^{1}$ School of Agriculture and Food Sciences, University of Queensland, Gatton, QLD, Australia. ${ }^{2}$ Agriculture, Commonwealth Science and Industrial Research Organisation, 306 Carmody Road, Brisbane, QLD, Australia. ${ }^{3}$ Swansea University Medical School, Swansea University, Singleton Park, Swansea SA2 8PP, Wales, UK. ${ }^{4}$ Institute for Molecular Biosciences, University of Queensland, St. Lucia, Brisbane, QLD, Australia. ${ }^{5}$ School of Veterinary and Life Sciences, Murdoch University, Murdoch, WA 6150, Australia. ${ }^{6} \mathrm{New}$ South Wales Department of Primary Industries, Armidale Livestock Industries Centre, University of New England, Armidale, NSW 2351, Australia.

Received: 14 August 2019 Accepted: 17 January 2020 Published online: 28 January 2020

\section{References}

1. Adoligbe C, Huangfu YF, Zan LS, Wang H. C/EBPalpha gene as a genetic marker for beef quality improvement. Genet Mol Res. 2015;14(3):9370-83.

2. Vernon RG. Lipid metabolism in the adipose tissue of ruminants. In: Christie W, editor. Lipid metabolism in ruminant animals. Oxford: Pergamon Press; 1981. p. 279-362.

3. Hocquette JF, Gondret F, Baeza E, Medale F, Jurie C, Pethick DW. Intramuscular fat content in meat-producing animals: development, genetic and nutritional control, and identification of putative markers. Animal. 2010; 4(2):303-19.

4. Pethick D, Harper G, Oddy V. Growth, development and nutritional manipulation of marbling in cattle: a review. Aust J Exp Agric. 2004;44: 705-15.

5. Harper G, Pethick D. How might marbling begin. Aust J Exp Agric. 2004;44: 653-62.

6. Smith SB, Crouse JD. Relative contributions of acetate, lactate and glucose to lipogenesis in bovine intramuscular and subcutaneous adipose tissue. J Nutr. 1984;114(4):792-800.

7. Tume R. The effects of environmental factors on fatty acid composition and the assessment of marbling in beef cattle: a review. Aust J Exp Agric. 2004; 44:663-8.

8. Smith SB. Marbling: Management of cattle to maximise the deposition of intramuscular adipose tissue; 2014.

9. May SG, Burney NS, Wilson JJ, Savell JW, Herring AD, Lunt DK, Baker JF, Sanders JO, Smith SB. Lipogenic activity of intramuscular and subcutaneous adipose tissues from steers produced by different generations of angus sires. J Anim Sci. 1995;73(5):1310-7.

10. Gardan D, Gondret F, Louveau I. Lipid metabolism and secretory function of porcine intramuscular adipocytes compared with subcutaneous and perirenal adipocytes. Am J Physiol Endocrinol Metab. 2006;291(2):E372-80.

11. Smith SB, Kawachi H, Choi CB, Choi CW, Wu G, Sawyer JE. Cellular regulation of bovine intramuscular adipose tissue development and composition. J Anim Sci. 2009;87(14 Suppl):E72-82.

12. Greenwood PL, Siddell JP, Walmsley BJ, Geesink GH, Pethick DW, McPhee MJ. Postweaning substitution of grazed forage with a high-energy concentrate has variable long-term effects on subcutaneous fat and marbling in Bos taurus genotypes. J Anim Sci. 2015;93:1-12.

13. Park SJ, Beak SH, Jung DJS, Kim SY, Jeong IH, Piao MY, Kang HJ, Fassah DM, Na SW, Yoo SP, et al. Genetic, management, and nutritional factors affecting intramuscular fat deposition in beef cattle - a review. Asian-Australas J Anim Sci. 2018;31(7):1043-61.

14. Wendel AA, Lewin TM, Coleman RA. Glycerol-3-phosphate acyltransferases: rate limiting enzymes of triacylglycerol biosynthesis. Biochim Biophys Acta. 2009;1791(6):501-6.

15. Tchkonia T, Lenburg M, Thomou T, Giorgadze N, Frampton G, Pirtskhalava T, Cartwright A, Cartwright M, Flanagan J, Karagiannides I, et al. Identification of depot-specific human fat cell progenitors through distinct expression profiles and developmental gene patterns. Am J Physiol Endocrinol Metab. 2007;292(1):E298-307.

16. Shan T, Liu W, Kuang S. Fatty acid binding protein 4 expression marks a population of adipocyte progenitors in white and brown adipose tissues. FASEB J. 2013;27(1):277-87.

17. Hausman GJ, Dodson MV, Ajuwon K, Azain M, Barnes KM, Guan LL, Jiang Z, Poulos SP, Sainz RD, Smith S, et al. Board-invited review: the biology and regulation of preadipocytes and adipocytes in meat animals. J Anim Sci. 2009;87(4):1218-46. 
18. Smas CM, Sul HS. Control of adipocyte differentiation. Biochem J. 1995; 309(Pt 3):697-710.

19. Wu T, Zhang Z, Yuan Z, Lo LJ, Chen J, Wang Y, Peng J. Distinctive genes determine different intramuscular fat and muscle fiber ratios of the longissimus dorsi muscles in Jinhua and landrace pigs. PLoS One. 2013;8(1): e53181.

20. Hudson NJ, Reverter A, Wang Y, Greenwood PL, Dalrymple BP. Inferring the transcriptional landscape of bovine skeletal muscle by integrating coexpression networks. PLoS One. 2009;4(10):e7249.

21. Fu Y, Luo L, Luo N, Zhu X, Garvey WT. NR4A orphan nuclear receptors modulate insulin action and the glucose transport system: potential role in insulin resistance. J Biol Chem. 2007;282(43):31525-33.

22. Bauman DE. Intermediary metabolism of adipose tissue. Fed Proc. 1976; 35(11):2308-13.

23. Kandutsch AA, Chen HW. Inhibition of sterol synthesis in cultured mouse cells by cholesterol derivatives oxygenated in the side chain. J Biol Chem. 1974;249(19):6057-61.

24. Gill S, Chow R, Brown AJ. Sterol regulators of cholesterol homeostasis and beyond: the oxysterol hypothesis revisited and revised. Prog Lipid Res. 2008; 47(6):391-404.

25. Ichikawa T, Sugiura H, Koarai A, Kikuchi T, Hiramatsu M, Kawabata H, Akamatsu K, Hirano T, Nakanishi M, Matsunaga K, et al. 25hydroxycholesterol promotes fibroblast-mediated tissue remodeling through NF-kappaB dependent pathway. Exp Cell Res. 2013;319(8):1176-86.

26. Cyster JG, Dang EV, Reboldi A, Yi T. 25-Hydroxycholesterols in innate and adaptive immunity. Nat Rev Immunol. 2014;14(11):731-43.

27. Duarte MS, Paulino PV, Das AK, Wei S, Serao NV, Fu X, Harris SM, Dodson MV, Du M. Enhancement of adipogenesis and fibrogenesis in skeletal muscle of Wagyu compared with Angus cattle. J Anim Sci. 2013;91(6):2938-46.

28. Sozen E, Ozer NK. Impact of high cholesterol and endoplasmic reticulum stress on metabolic diseases: an updated mini-review. Redox Biol. 2017;12: 456-61.

29. Varghese M, Griffin C, Singer K. The role of sex and sex hormones in regulating obesity-induced inflammation. Adv Exp Med Biol. 2017;1043:65-86.

30. Liu X, Yu X, Zack DJ, Zhu H, Qian J. TiGER: a database for tissue-specific gene expression and regulation. BMC Bioinformatics. 2008;9:271.

31. Greenwood PL, Cafe LM, Hearnshaw H, Hennessy DW, Thompson JM, Morris SG. Long-term consequences of birth weight and growth to weaning on carcass, yield and beef quality characteristics of Piedmontese- and Wagyusired cattle. Aust J Exp Agric. 2006;46:257-69.

32. Abdel-Khalik J, Yutuc E, Crick PJ, Gustafsson JA, Warner M, Roman G, Talbot K, Gray E, Griffiths WJ, Turner MR, et al. Defective cholesterol metabolism in amyotrophic lateral sclerosis. J Lipid Res. 2017;58(1):267-78.

33. Reverter A, Barris W, McWilliam S, Byrne KA, Wang YH, Tan SH, Hudson N, Dalrymple BP. Validation of alternative methods of data normalization in gene co-expression studies. Bioinformatics. 2005;21(7):1112-20.

34. Caraux G, Pinloche S. PermutMatrix: a graphical environment to arrange gene expression profiles in optimal linear order. Bioinformatics. 2005;21(7): $1280-1$.

35. Hudson NJ, Reverter A, Dalrymple BP. A differential wiring analysis of expression data correctly identifies the gene containing the causal mutation. PLoS Comput Biol. 2009;5(5):e1000382.

36. Bottje W, Kong BW, Reverter A, Waardenberg AJ, Lassiter K, Hudson NJ. Progesterone signalling in broiler skeletal muscle is associated with divergent feed efficiency. BMC Syst Biol. 2017;11(1):29.

37. Eden E, Lipson D, Yogev S, Yakhini Z. Discovering motifs in ranked lists of DNA sequences. PLoS Comput Biol. 2007;3(3):e39.

38. Eden E, Navon R, Steinfeld I, Lipson D, Yakhini Z. GOrilla: a tool for discovery and visualization of enriched $\mathrm{GO}$ terms in ranked gene lists. BMC Bioinformatics. 2009;10:48.

\section{Publisher's Note}

Springer Nature remains neutral with regard to jurisdictional claims in published maps and institutional affiliations.

Ready to submit your research? Choose BMC and benefit from:

- fast, convenient online submission

- thorough peer review by experienced researchers in your field

- rapid publication on acceptance

- support for research data, including large and complex data types

- gold Open Access which fosters wider collaboration and increased citations

- maximum visibility for your research: over $100 \mathrm{M}$ website views per year

At BMC, research is always in progress.

Learn more biomedcentral.com/submissions 